\title{
Employment and the Great Recession: The Role of Real Wages
}




\title{
WP/15/229
}

\section{IMF Working Paper}

\section{Employment and the Great Recession: The Role of Real Wages}

\author{
by Bas B. Bakker
}

IMF Working Papers describe research in progress by the author(s) and are published to elicit comments and to encourage debate. The views expressed in IMF Working Papers are those of the author(s) and do not necessarily represent the views of the IMF, its Executive Board, or IMF management. 


\title{
IMF Working Paper
}

\author{
European Department
}

\section{Employment and the Great Recession: The Role of Real Wages}

\author{
Prepared by Bas B. Bakker ${ }^{1}$
}

October 2015

\section{IMF Working Papers describe research in progress by the author(s) and are published to} elicit comments and to encourage debate. The views expressed in IMF Working Papers are those of the author(s) and do not necessarily represent the views of the IMF, its Executive Board, or IMF management.

\begin{abstract}
This paper argues that the sharp increase in unemployment in a number of advanced countries during the Great Recession was not just cyclical (the result of a lack of aggregate demand); the degree of adjustment of real wages and the impact this had on labor productivity also played a role. In many countries, post-2007 employment losses were modest, as real wages adjusted when the economy slowed down. But in some countries real wage growth stayed too high for too long. The result was large-scale labor shedding, which boosted labor productivity but also contributed to a sharp rise in unemployment. In this context, the paper discusses the different experiences of the UK (where employment increased) and Spain (where it fell sharply), and finds that almost two thirds of the employment losses in Spain resulted from the failure of real wages to adjust adequately.
\end{abstract}

JEL Classification Numbers: E32, J6, J23, J30

Keywords: Great Recession, real wages, employment, unemployment, Okun's law

Author's E-Mail Address: bbakker@imf.org

\footnotetext{
${ }^{1}$ This paper has benefited from extensive discussions with Joshua Felman and Leslie Lipschitz. I would also like to thank Laurence Ball, Tamim Bayoumi, Craig Beaumont, Helge Berger, Olivier Blanchard, James Daniel, Jorg Decressin, Christian Ebeke, Gerhard Fenz, Alessandro Giustiani, Russell Kincaid, Frank Lakwijk, Kate Langdon, Daniel Leigh, Prakash Loungani, Christian Ragacs, Martin Schneider, Flore de Sloove, Siegfried Steinlein, Marzi Taheri, Peter Walker, and Li Zeng for helpful comments on earlier versions of this paper.
} 


\section{Contents}

Executive Summary $\quad \underline{4}$

1 Introduction $\underline{5}$

2 The Importance of Wage Adjustment: Looking at the Data $\underline{8}$

2.1 Cross-Country Evidence . . . . . . . . . . . . . . . $\underline{8}$

2.2 Spain vs the United Kingdom . . . . . . . . . . . . . . 13

3 Okun's Law, Cyclical and Structural Unemployment $\underline{20}$

3.1 Okun's Law . . . . . . . . . . . . . . . . . 20

3.2 Sensitivity Analysis . . . . . . . . . . . . . . . 25

4 The Output Gap and Unemployment $\underline{29}$

4.1 The Output Gap and Cyclical Unemployment . . . . . . . . . . . . $\underline{29}$

5 The Output Gap and the Employment Gap and Overall Employment $\underline{32}$

6 Real Wages and the Structural Employment Rate $\underline{37}$

6.1 The Framework . . . . . . . . . . . . . . . . . . $\underline{37}$

6.2 Interpretation of the Wage Pressure Variable . . . . . . . . . . . $\underline{40}$

6.3 Econometrics . . . . . . . . . . . . . . . . .

7 The Relationship between the Overall Employment Rate, Output Gap and Real Wages $\underline{43}$

7.1 The Framework . . . . . . . . . . . . . . . . . . .

7.2 Econometric Analysis . . . . . . . . . . . . . . . $4 \underline{43}$

7.3 Application to Spain and the United Kingdom . . . . . . . . . . 4 45

7.4 Sensitivity Analysis . . . . . . . . . . . . . . . . . 4 48

8 Conclusion $\underline{54}$

References $\quad \underline{56}$

Data sources $\quad \underline{57}$

Annex 1: Derivation using a CES-function $\quad \underline{58}$

Annex 2: The Wage Share $\quad \underline{59}$

Annex 3: Derivation using a Cobb-Douglas production function $\underline{60}$ 


\section{Executive Summary}

Since the onset of the Great Recession there have been large differences in employment growth among advanced countries, with employment declining by 14 percent in Spain, and increasing by 6 percent in Germany. What explains these differences? Why did employment rates fall so sharply in some countries, but not in others?

This paper argues that the sharp losses in employment in some countries were not just the result of shortfalls in demand, but also of real wages that increased too rapidly. In many countries, post-2007 employment losses were modest, as real wages adjusted when the economy slowed down. But in some countries real wage growth stayed too high for too long. The result was large-scale labor shedding; this boosted labor productivity but also contributed to a sharp rise in unemployment.

The idea that the adjustment of real wages matters for employment is not new, but was debated extensively in the early 1980s. After the two oil shocks, unemployment had risen sharply in Europe, but not in the U.S., raising the question whether the rise in unemployment in Europe was really only cyclical. A number of authors suggested that the high level of unemployment in many European countries was not just the result of insufficient aggregate demand; in countries where wages had not adjusted after the two oil shocks, and the entire burden of adjustment had fallen on profits, firms shed labor to restore profits, and employment suffered as a result. This paper argues that a similar mechanism has been at work in the Great Recession.

To demonstrate that the differences were not just the result of shortfalls in demand, the paper shows for a sample of 14 countries for the 1970-2014 period that changes in the output gap explain only a portion - in some countries, only a small portion - of the changes in unemployment rates. In other words, much of the changes in unemployment rates are the result of changes in structural unemployment. The same conclusion holds true for the employment rate.

To demonstrate that real wages mattered, the paper shows that the structural employment rates can be explained by a real wage indicator derived from standard neoclassical production theory - that is, the ratio of the average real wage to potential GDP per working age capita.

To further illustrate the role of real wages, the paper discusses the different experience of the United Kingdom (which saw an increase in the employment rate between 2007 and 2014 from 72 to 73 percent) and Spain (which saw a decline from 68 percent to 59 percent). The econometric results in the paper confirm that the differences were in large part due to the different behavior of real wages, which increased by 12 percent in Spain, but declined by 3 percent in the UK. They also suggest that almost two thirds of the decline in the employment rate in Spain was the result of the increase in the average real wage relative to potential GDP per capita. 


\section{Introduction}

Since the onset of the global crisis there have been large differences in employment changes and labor productivity growth among advanced countries. What explains these differences? Why have unemployment and productivity increased so sharply in, for example, Spain, but not in the United Kingdom?

- Some authors have argued that the large rise in unemployment in some countries has been largely cyclical. In this interpretation, high unemployment in, for example, Spain reflects a combination of a high output gap and a high sensitivity of unemployment to the output gap (Ball, Leigh and Loungani, 2013).

- Some other authors have argued that the sharp rise in unemployment in some countries has been structural, reflecting the loss of competitiveness during the boom years (Thimann, 2015).

This paper contributes to the debate by providing evidence that part of the increase in unemployment rates in some countries in the Great Recession was not just the result of shortfalls in demand, but also of real wages that have increased too rapidly.

To demonstrate this, we first show that output gap developments explain only part of the changes in unemployment:

- Cyclical unemployment is explained well by changes in the output gap - Okun's law holds.

- Overall unemployment is not explained well by changes in the output gap - much of the changes in unemployment are structural rather than cyclical.

- The same conclusions hold if we focus on employment rather than unemployment: the output gap explains cyclical employment well, but not overall employment.

Having concluded that part of the sharp increase in unemployment in some countries has indeed been structural, we then raise the question why structural unemployment would have increased. To answer the question, we turn to an argument advanced in the early 1980s. After the two oil shocks, unemployment had risen sharply in Europe, but not in the U.S., raising the question whether the rise in unemployment in Europe was really only cyclical. A number of authors suggested that wage adjustment explained the difference: countries had been confronted with similar relative price changes during the 1970s - principally large and sudden increases in the costs of raw materials and fuels - but countries differed in their adjustment to these changes. At one extreme, real wages (or the growth of real wages) remained unchanged, thereby pushing onto profits the entire burden of adjustment to the input price shocks; at the other extreme, real wages fell sharply, thereby maintaining profit shares. In countries where wages had not adjusted after the two oil shocks, and the entire 
burden of adjustment had fallen on profits, firms had shed labor to restore profits, and employment had suffered as a result. ${ }^{1}$ Blanchard (1997) summarizes the argument:

"There is wide consensus that these shifts came from the failure of wages to adjust to the productivity slowdown and the adverse supply shocks of the 1970s. In any case, their initial effect was to decrease profit rates and capital shares. Over time, firms reacted by moving away from labor, leading to a steady increase in unemployment, a recovery, and even an increase in capital shares."

Figure 1. Keynesian and Classical Unemployment

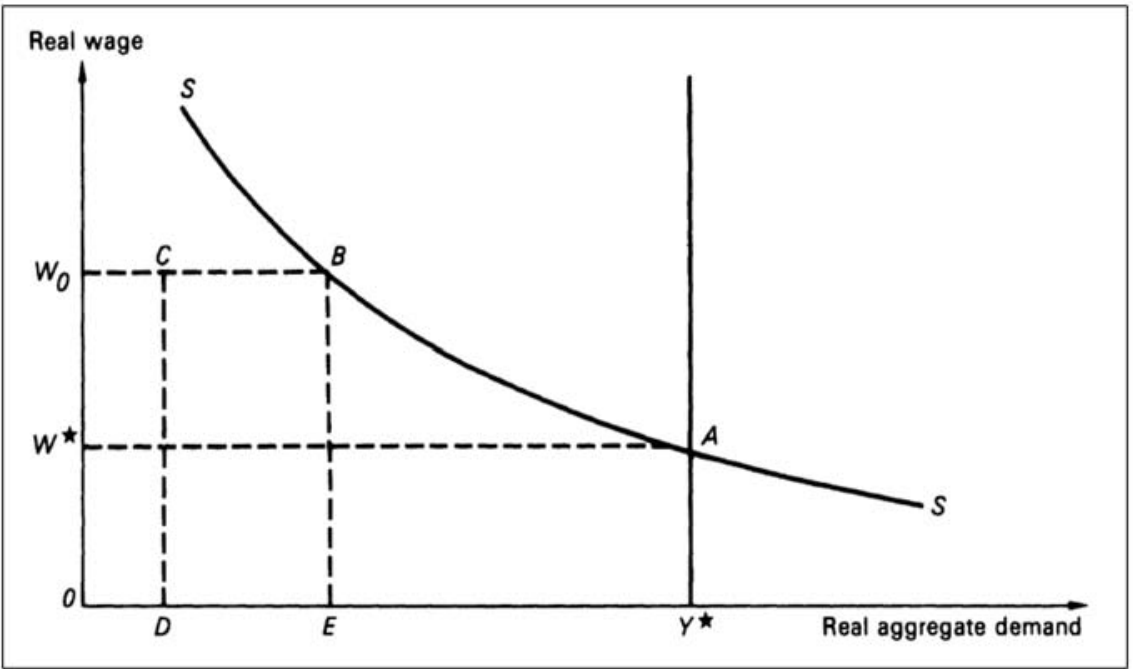

The argument is depicted in Figure 1, which is borrowed from Lipschitz and Schadler (1984). $S S$ is the locus of points at which real wages are such that firms are willing to supply the amount of output demanded. It embodies a given state of technology and stock of capital and is negatively sloped to indicate that an increase in employment requires a reduction in real wages. The vertical line drawn at $Y^{*}$ represents full employment. The area to the left of $S S$ represents Keynesian unemployment. The area to the left of the full employment line $\left(Y^{*}\right)$, but on or to the right of $S S$, represents classical (highwage) unemployment. At point $C$, for example, output is constrained by demand, which amounts to $O D$, while at the given real wage rate $W_{0}$ firms would willingly produce $O E$. Clearly, demand stimulus could increase output to point $B$. At this point, however, real

\footnotetext{
${ }^{1}$ See, for example, Lipschitz and Schadler (1984); Arthus (1984); Bruno and Sachs (1979, 1985), Sachs (1983).
} 
wages become the operative constraint. Supply would be impervious to further demand expansion unless real wages were reduced. At any real wage above $W^{*}$, there will not be full employment. Unemployment may be purely classical, as at point $B$, or a combination of classical and Keynesian, as at point $C$.

This paper argues that a similar mechanism has been at work in the Great Recession. In many countries, employment losses post 2007 were modest, as real wages adjusted when the economy slowed down. But in some countries real wage growth stayed too high for too long. The result was large-scale labor shedding, which boosted labor productivity but also contributed to a sharp rise in unemployment.

The paper is organized as follows. In section 2 we take a closer look at the data. In section 3 we discuss Okun's law and the difficulties in breaking down unemployment into a cyclical and a structural component. In section 4 we show that the output gap explains cyclical unemployment, but not the overall unemployment rate. In section 5 we show the same for the employment rate. In section 6 we discuss the link between real wages and the structural employment rate. In section 7 , we link the overall employment rate to both the output gap and real wages. Section 8 concludes. 


\section{The Importance of Wage Adjustment: Looking at the Data}

\subsection{Cross-Country Evidence}

There have been large cross-country differences in employment growth during the 2007-14 period. Employment declined by 14 percent in Spain, but increased by 6 percent in Germany (Figure 2). ${ }^{2}$ There have been similar difference in changes and the employment and unemployment rate. In some countries (Spain, Ireland, Portugal, Italy), the employment rate has dropped sharply, while in some others (Germany, Austria, Japan) it is now higher than in 2007 (Figure 3).

These differences seem to go beyond what can be explained by differences in output growth. Clearly, differences in GDP growth have been important: GDP growth in Germany (where employment expanded) has been much stronger than in Ireland and Spain, which saw large employment contractions. But output losses in Italy and Finland have been similar to those in Spain and Portugal, yet employment losses in the former have been much smaller than in the latter.

Figure 2: Change in Employment, 2007-14

(Percent)

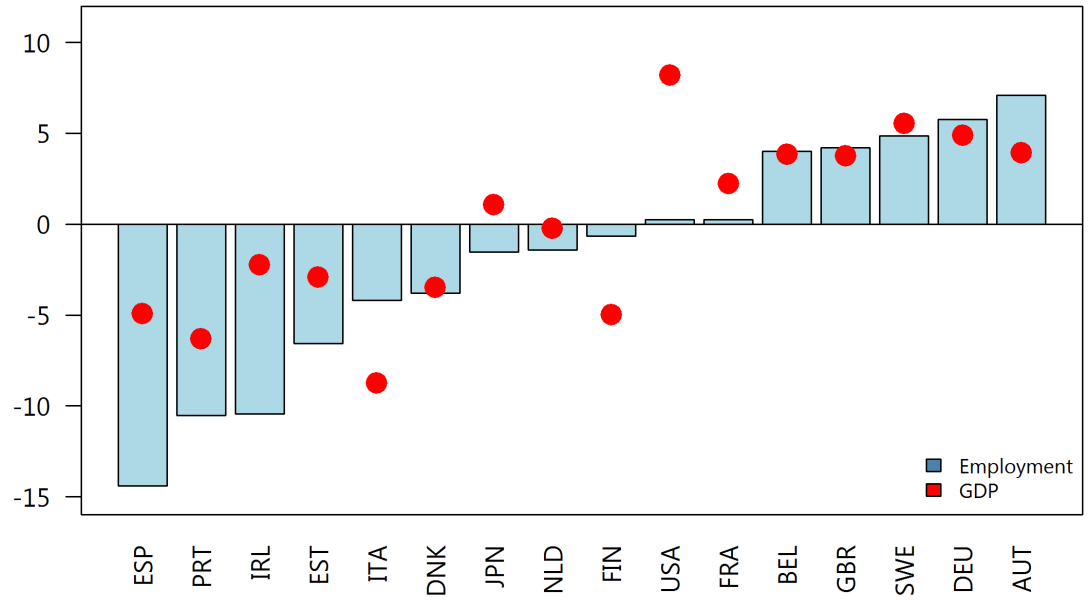

\footnotetext{
${ }^{2}$ Most of the data in the paper are from AMECO, the annual macro-economic database of the European Commission's Directorate General for Economic and Financial Affairs (DG ECFIN), available at http: //ec.europa.eu/economy_finance/db_indicators/ameco/index_en.htm. Variables and data sources are discussed in the Data sources section at the end of the paper.
} 
Figure 3: Change in Employment and Unemployment Rate, 2007-14

(Percentage points)
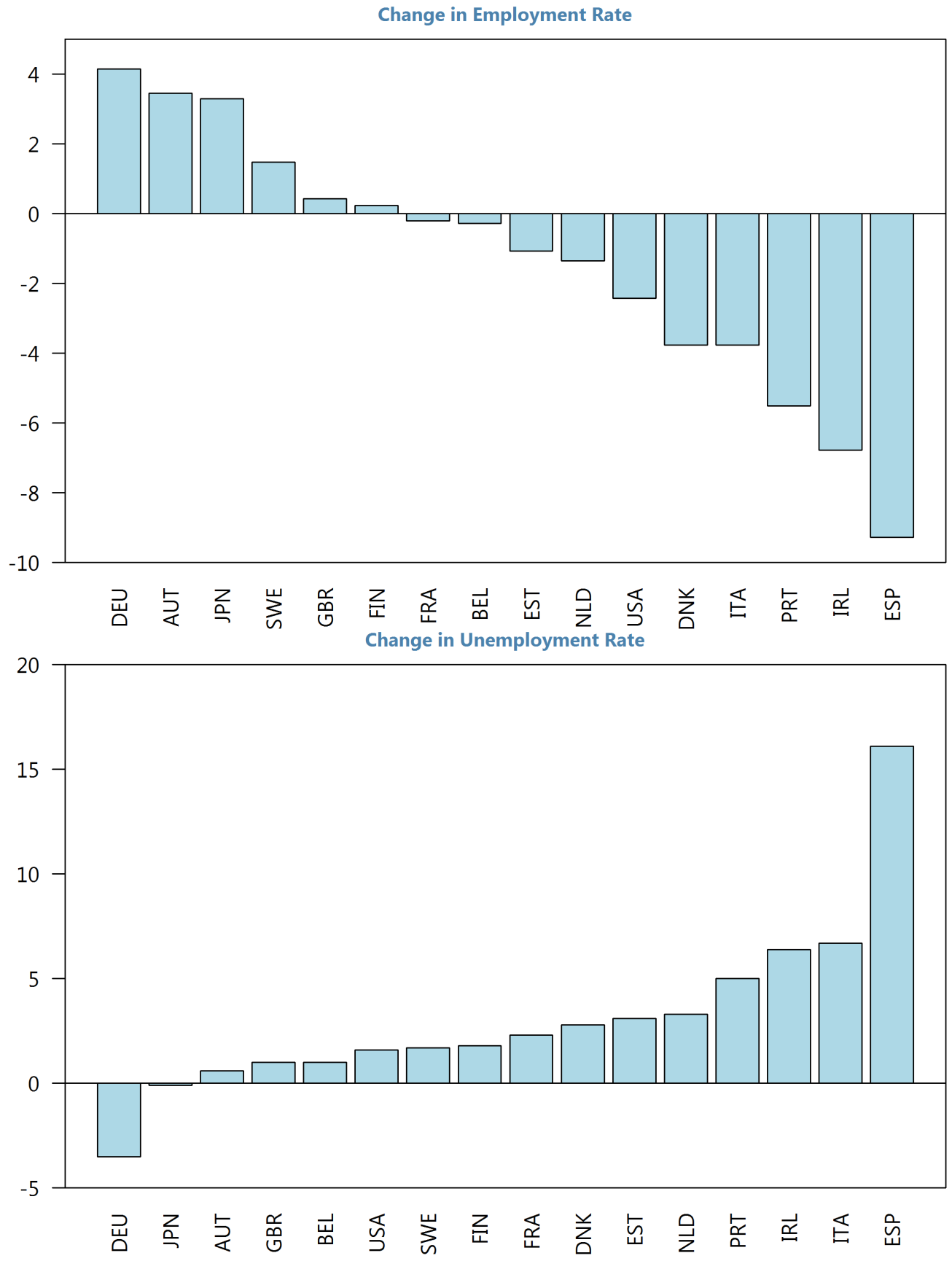
There have also been large differences in labor productivity growth and real wage growth:

- Productivity growth in the United Kingdom slowed from 16 percent in the 2000-2007 period to -3 percent in the 2007-14 period (Figure 4). By contrast, productivity growth in Spain accelerated, from -1 percent in 2000-2007 to +12 percent in 2007-14.

- Real wages increased by 12 percent in Spain, but declined by 3 percent in the United Kingdom (Figure 5).

Figure 4. Labor Productivity Growth: 2007-14 vs. 2000-07

(Percent)

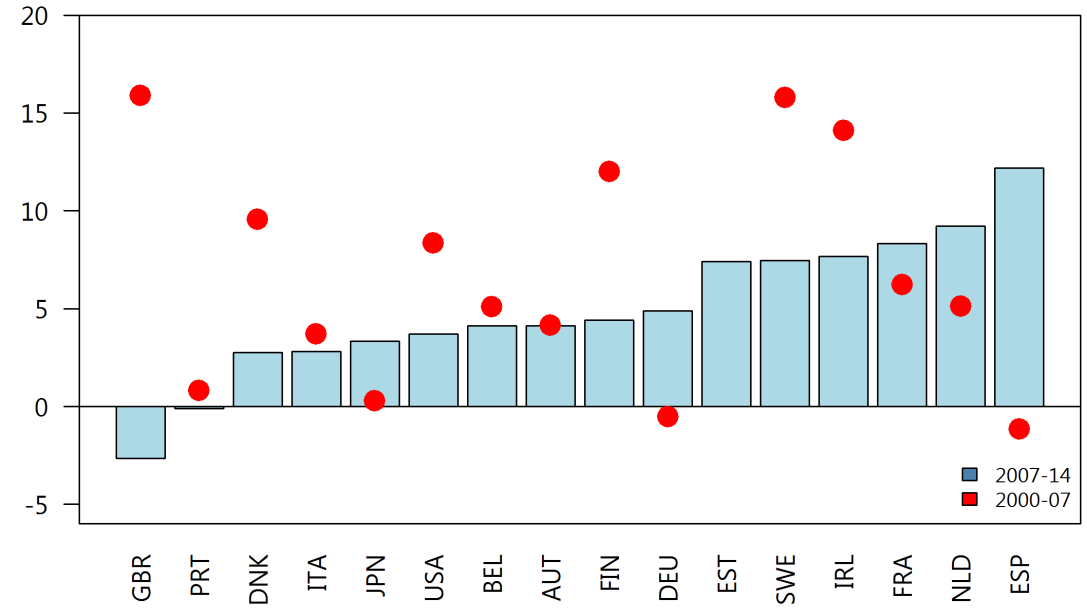

As will be discussed in more detail in section 6 , in the steady state, to keep the employment rate constant, wages should grow at the rate of technological progress, which in turn will determine potential GDP growth per working age person. So, what matters for employment is wage growth relative to potential GDP growth per working age person. Figure 5 shows that on this metric wage growth in some countries was particularly high, as potential GDP per working age person growth in some countries was near zero, or even negative. ${ }^{3}$ There is indeed a clear link between the extent to which real wage growth exceeded potential GDP per working age capita growth, and employment losses (Figure 6).

\footnotetext{
${ }^{3}$ We calculated potential GDP per working age capita using an HP-filter on annual data for 1970-2014. Germany, for which GDP data are only available from 1991 onwards in the Ameco database, was dropped for this reason. It should be acknowledged that there is controversy about potential growth in these countries; this controversy will be discussed below in section 3.2 .
} 
Figure 5: Change in Real Wages and Potential GDP per Working Age Capita, 2007-14 (Percent)

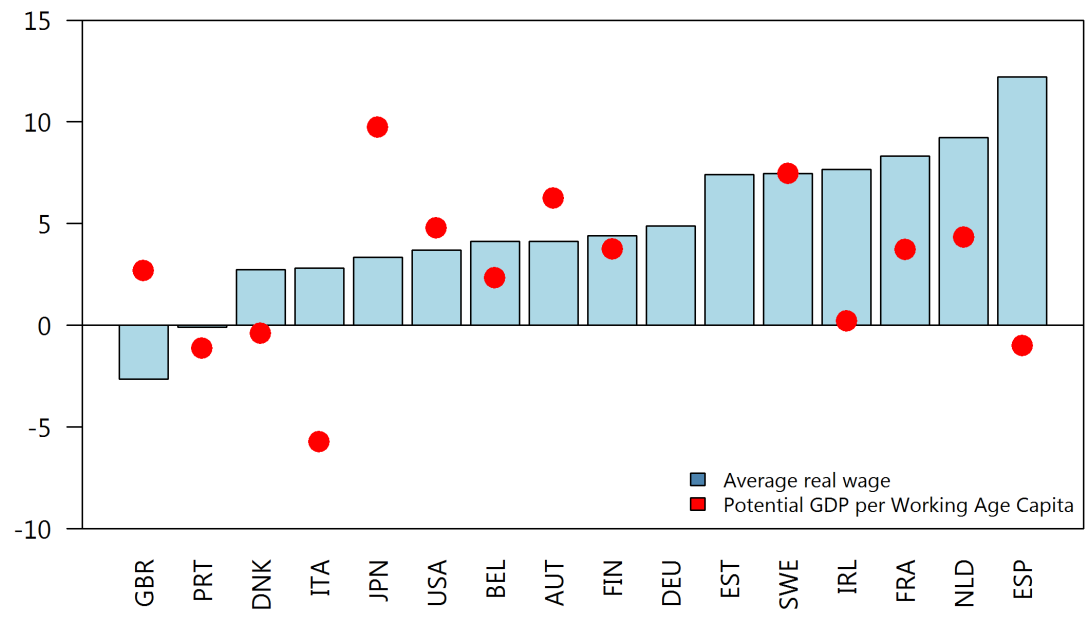

Figure 6. Change in the Average Real Wage/Potential GDP per Working Age Capita Ratio, and the Employment Rate, 2007-14

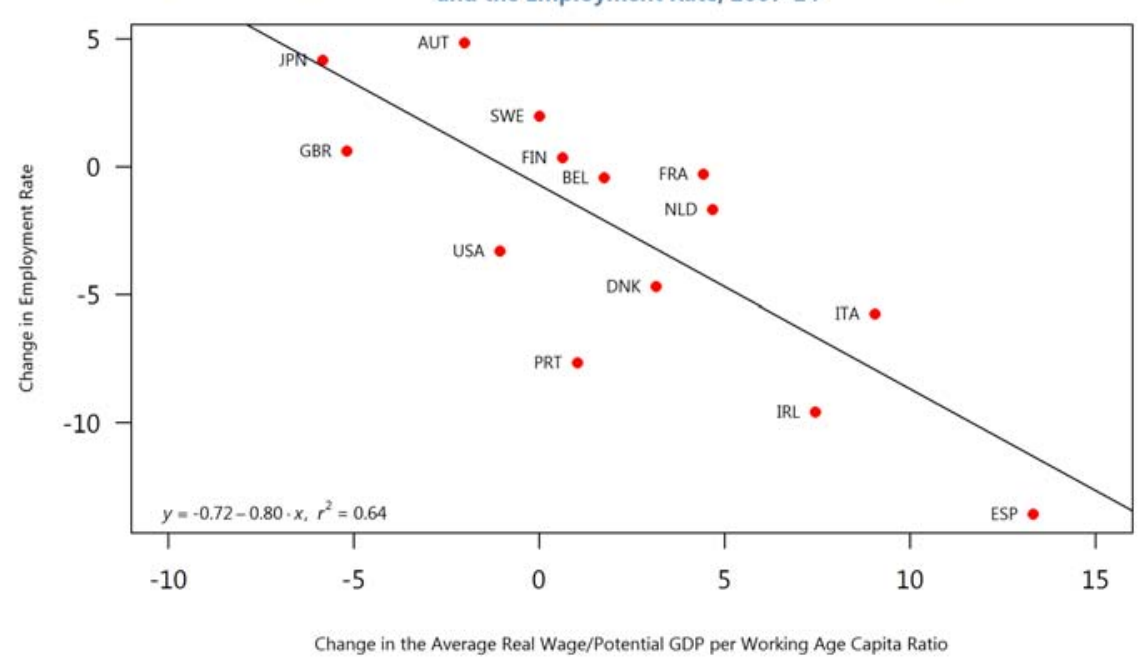

11

CInternational Monetary Fund. Not for Redistribution 
Countries with fast wage growth saw large drops in employment, while in countries where wage growth remained modest relative to per capita GDP growth, employment actually increased.

It should be noted that differences in employment growth are not the result of changes in hours worked per employee, as for most countries ${ }^{4}$ changes in employment measured in persons are very similar to changes in employment measures in total hours (Figure 7). ${ }^{5}$

Figure 7: Employment Growth: Persons vs Total Hours, 2007-14

(Percent)

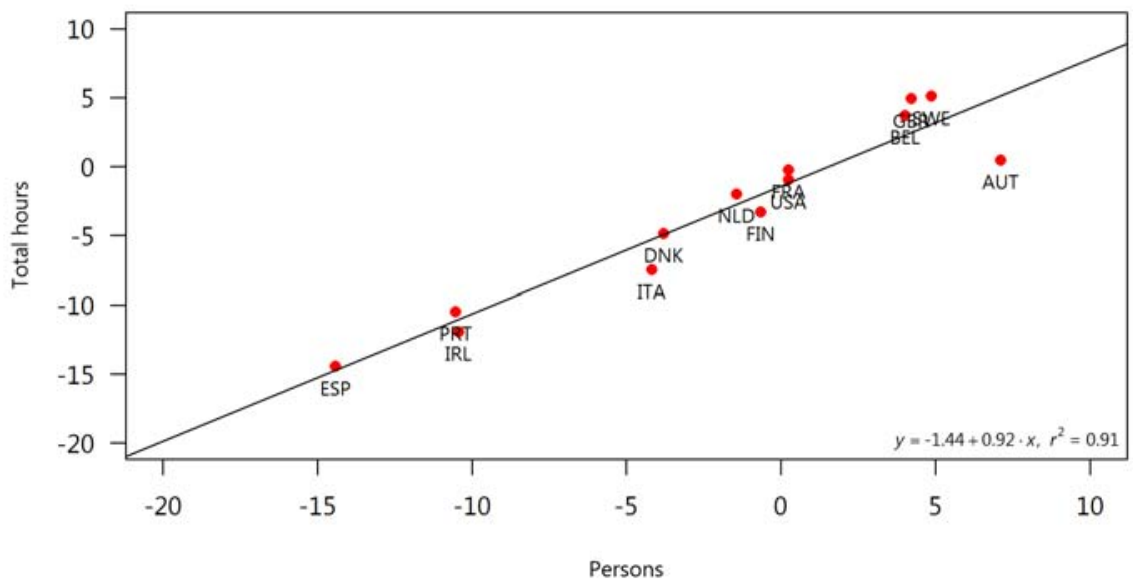

\footnotetext{
${ }^{4}$ In Austria, employment growth in hours was significantly slower than employment growth in persons.

${ }^{5}$ In this paper we focus on employment rather than total hours worked, as Ameco does not have data on real wages per hour.
} 


\subsection{Spain vs the United Kingdom}

The very different experience of Spain and the UK during the great recession provides a good illustration of the importance of timely wage adjustment (Figure 8):

- In the UK, employment fell only briefly, and then recovered strongly. Employment initially fell by 11/2 percent between 2008 and 2010, and the unemployment rate increased from 5.3 percent in 2007 to 8.1 in 2011. But in 2010, employment started growing again; by 2012, the pre-crisis employment level had been exceeded, and by 2014, employment was 4 percent higher than in 2007. Employment growth in the UK during 2007-14 was not much lower than during the 2000-07 period (7.0 percent). ${ }^{6}$

- In Spain, as noted, employment fell for an extended time, and by a large amount. Employment fell by 16 percent between 2008 and 2013, and unemployment rose from 8.1 percent in 2007 to 26.1 percent in 2013. Only in 2014 did employment start to recover. Overall, in 2014, employment was 15 percent below the 2007 level. $^{7}$

What could have explained this difference? Not the severity of the downturn. The UK saw a deeper recession in 2009, and even by 2012, the decline in GDP from the 2007 level was similar in both countries.

Nor are the employment differences the result of changes in the sectoral composition of employment. True, employment in the construction sector in Spain dropped by over 60 percent between 2007 and 2013. But while losses in the construction sector were important, they explain only part of the cross-country differences, as employment losses in other sectors also exceeded those in other countries. Spain also saw a drop in employment of more than 25 percent in industry, and almost 5 percent in services. Indeed, even if Spain had not had any losses in the construction sector, its employment losses would still have exceeded those in other countries (Figure 9). Moreover, productivity growth in Spain accelerated in each sector (Figure 10) - in contrast with the United Kingdom.

\footnotetext{
${ }^{6}$ The working age population in the UK increased by 3.0 percent, down from 6.0 percent in 2000-2007 period

${ }^{7}$ Notably, however, the rate of growth of the working age population in the UK fell from 6.0 percent in 2000-2007 to 3 percent in $2007-2014$.
} 
Figure 8: Spain and UK: Real GDP, Labor Productivity and Employment (Percent change)
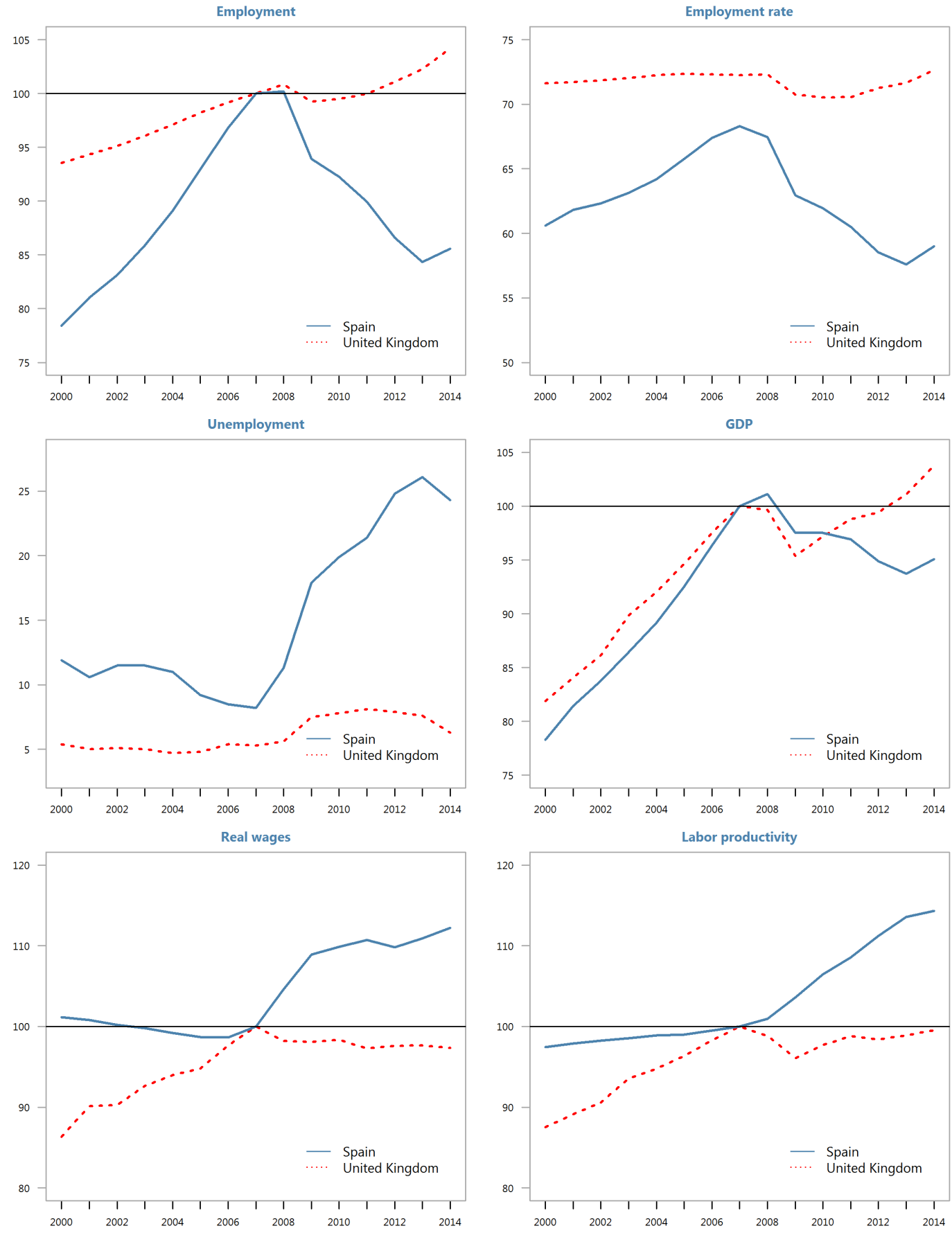

14

CInternational Monetary Fund. Not for Redistribution 
Figure 9: Employment Changes by Sector, 2007-13 (Percent)

Industry (excluding construction)
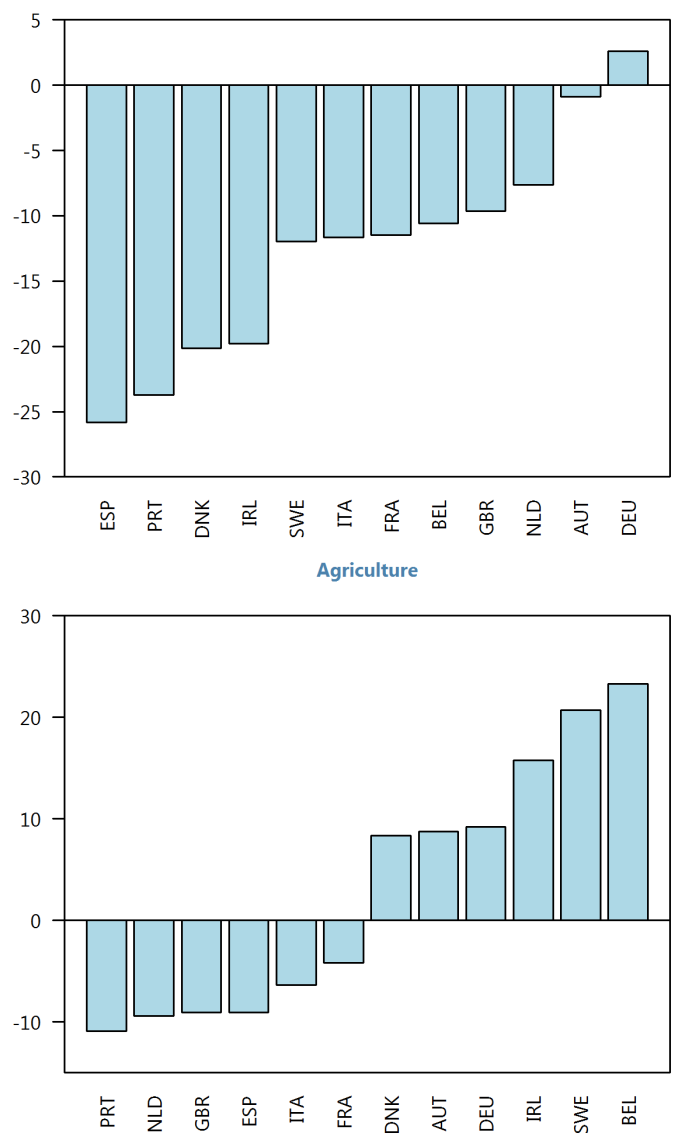

Services
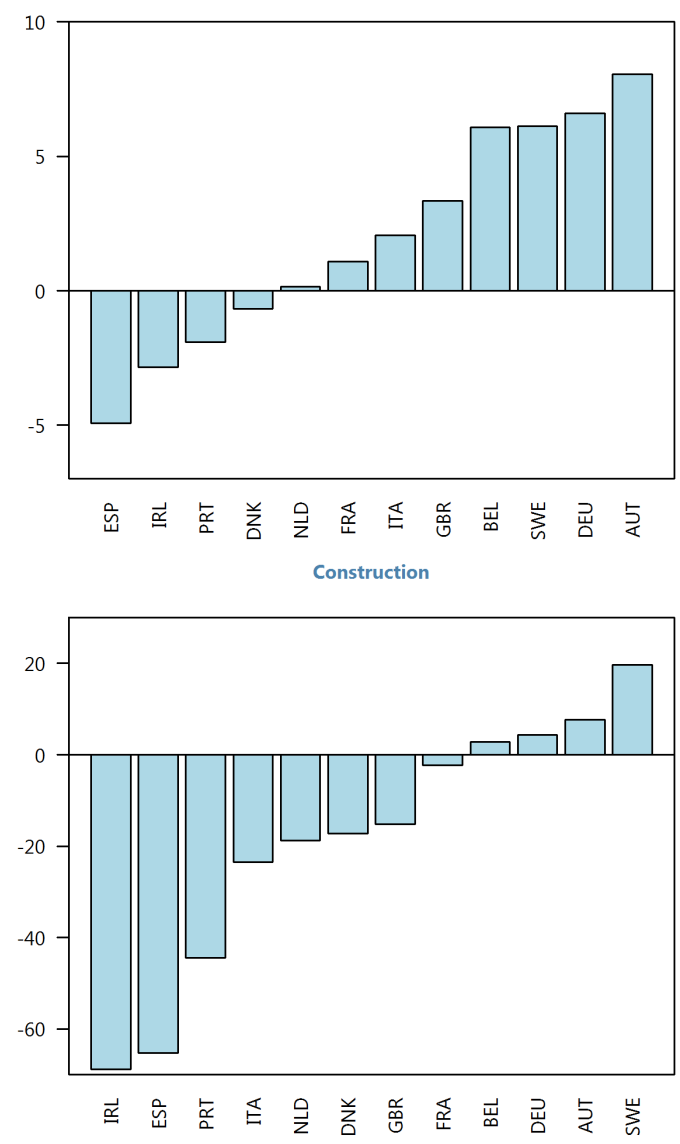

Sectoral Contributions to Employment Growth, 2007-13 Percentage points)

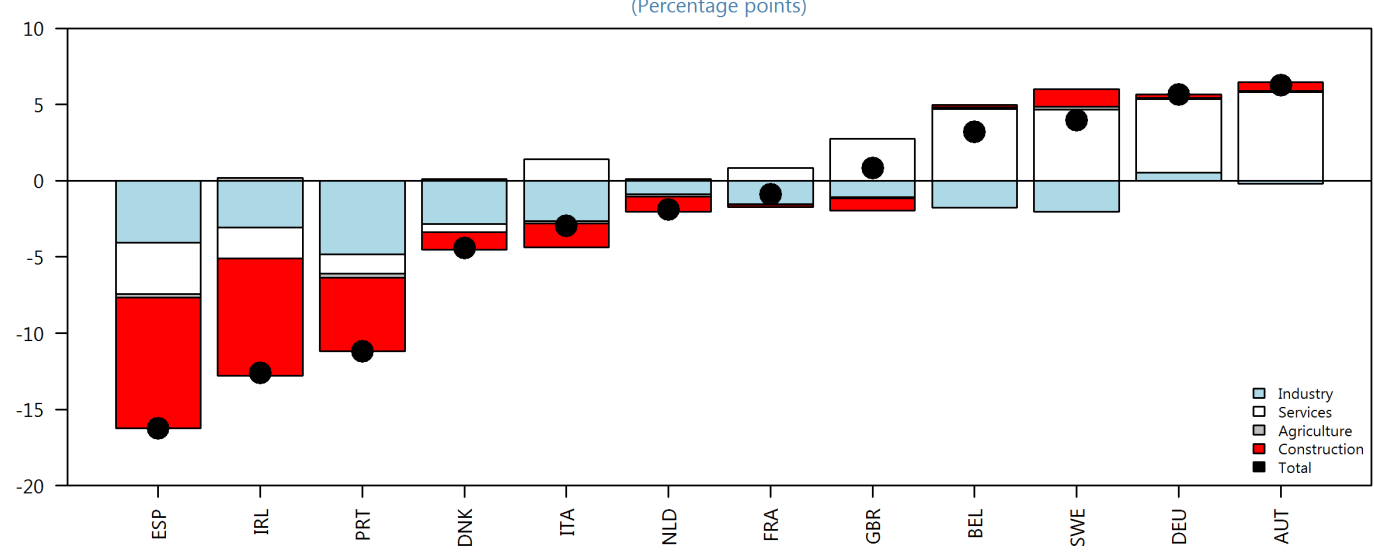


Figure 10: Spain and UK: Labor Productivity by Sector, 2000-14

$$
\text { (2007=100) }
$$
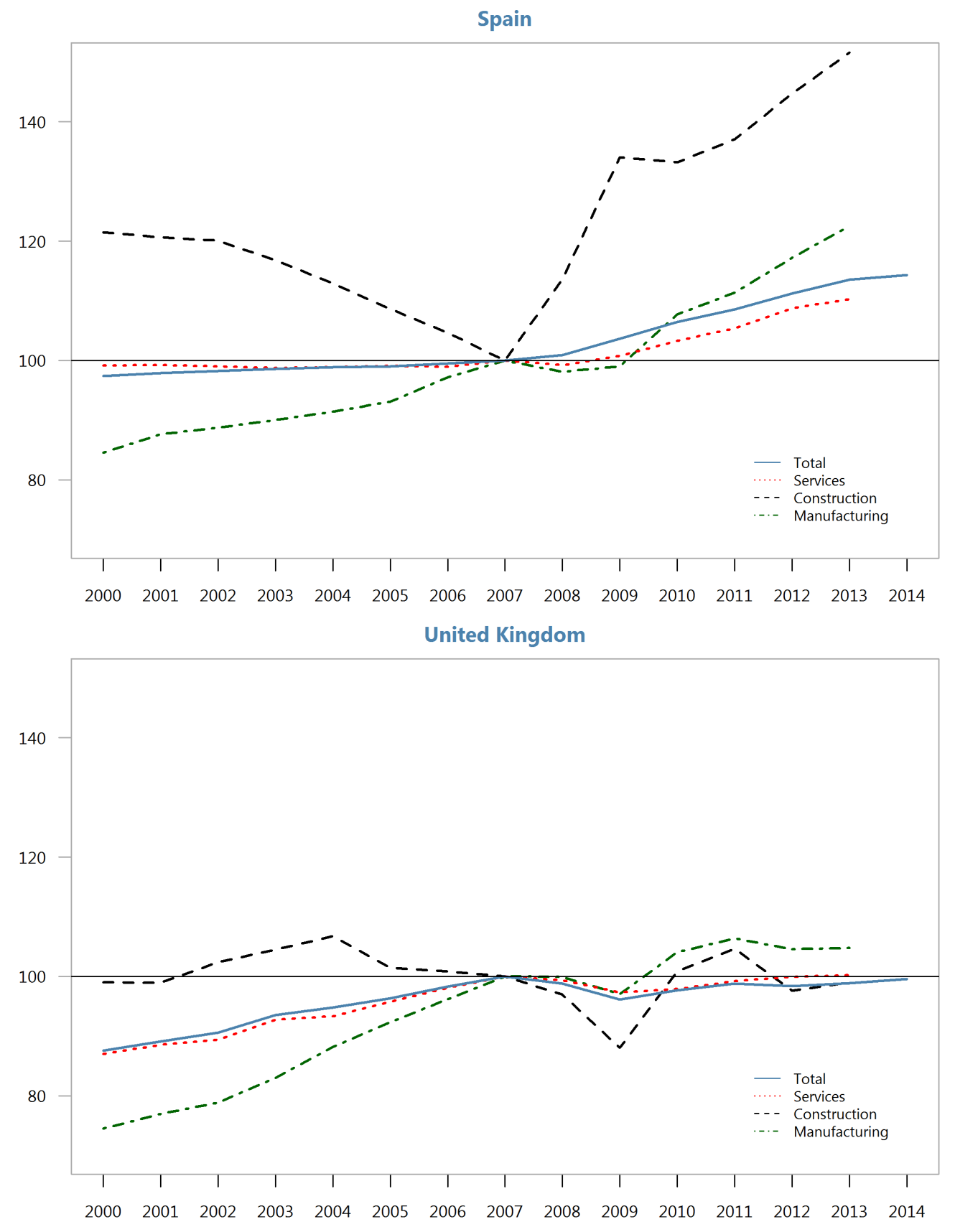
Rather, the differences between Spain and the UK can be explained by the behavior of real wages. Wage adjustment during the Great Recession was much faster in the UK than in Spain:

- In Spain, real wages were accelerating when the economy went into recession, and they adjusted only with a considerable lag. By contrast, in the UK, real wages adjusted very quickly (Figure 11, top).

- As a result, by 2014, real wages in Spain were 12 percent above the 2007 level. In the United Kingdom, they were 3 percent below the 2007 level.

- The slower adjustment of real wages in Spain was partly the result of slow adjustment of nominal wages. But it was further exacerbated by the drop in GDP inflation (Figure 11, bottom)

It should be noted that high wage growth in Spain does not seem the result of compositional effects. In theory, compositional effects could distort the picture: if employment cuts were concentrated among low-wage workers, average wages would rise, even if the wages of those employed had not changed. In practice however, this does not seem to have been the case:

- If composition effects had been important, wage drift - the difference between the increase in average wages and the increase in wage scales - would have been positive Figure 12 shows that before the crisis, average wages rose much faster than wage scales, but after 2007 this reversed. ${ }^{8}$

- The share of low wage jobs in Spain increased between 2006 and 2010 (Table 1). ${ }^{9}$

Economic theory suggests that the higher real wage in Spain should have elicited a drop in the employment/output ratio to the point where higher productivity was consistent with these real wages. And, indeed, labor productivity did see a counter-cyclical rise in Spain. By 2014 labor productivity in Spain was 14 percent higher than in 2007. In contrast, in the UK where wage adjustment was rapid and labor shedding modest and short-lived, labor productivity fell: by 2014 it had still not exceeded the 2007 level.

\footnotetext{
${ }^{8}$ Wage agreements in Spain are automatically extended to the entire province or industry, even to employees and firms that did not participate in the bargaining (Jaumotte, 2011).

${ }^{9}$ Low-wage earners are defined as those employees earning two thirds or less of the national median gross hourly earnings in a particular country. In Spain, in the two sectors with the largest employment losses - construction and manufacturing - the share of low wage jobs is lower than that in the economy as a whole. Interestingly, the share of low wages in construction and manufacturing is also much lower than that in most other countries.
} 
Figure 11: Wage Growth: Spain and United Kingdom, 2000-14 (Percent change)
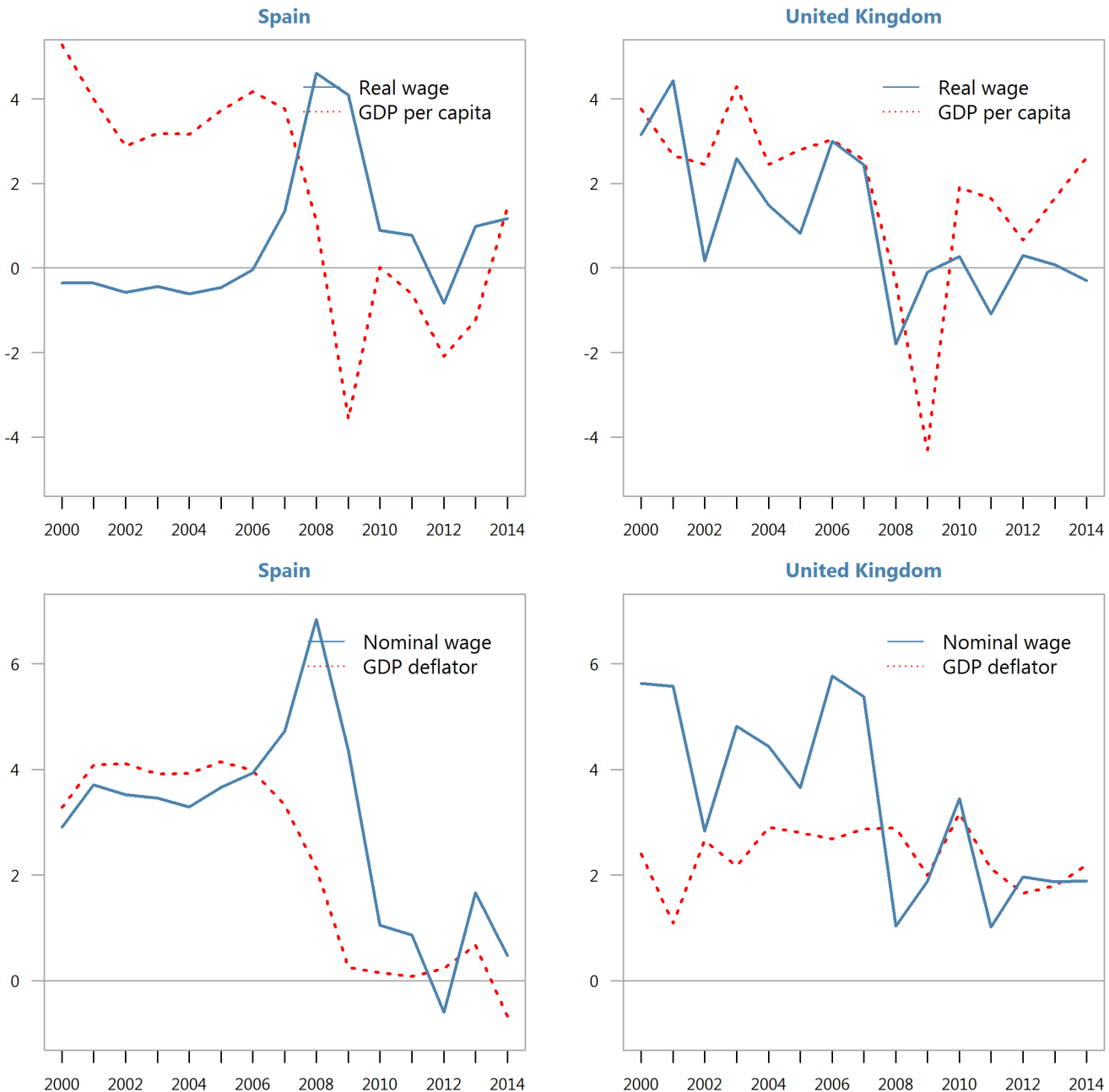
Figure 12: Spain: Wage Drift 2000-14 (Percent)

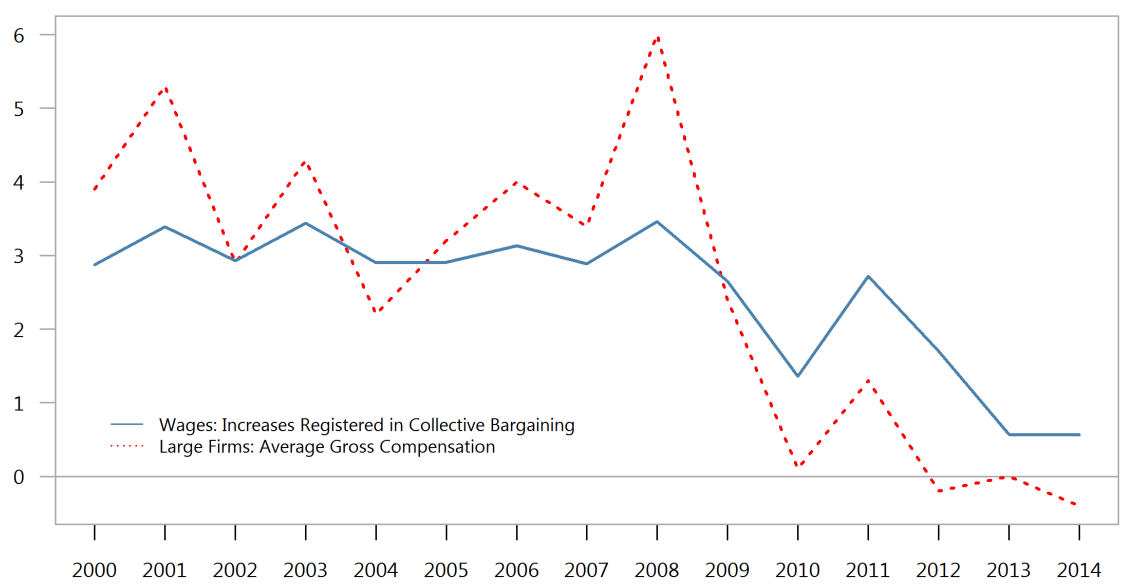

Table 1: Low Wage Earners as Share of All Employment

\begin{tabular}{lrr}
\hline & 2006 & 2010 \\
& & \\
\hline Sweden & 1.8 & 2.5 \\
Finland & 4.8 & 5.9 \\
France & 7.1 & 6.1 \\
Belgium & 7.6 & 6.4 \\
Denmark & 9.0 & 7.7 \\
Italy & 10.3 & 12.4 \\
Spain & 13.4 & 14.7 \\
Euro area (17 countries) & 14.4 & 14.7 \\
Austria & 14.2 & 15.0 \\
Portugal & 20.7 & 16.1 \\
European Union (27 countries) & 16.8 & 16.9 \\
Netherlands & 17.7 & 18.1 \\
Ireland & 21.4 & 20.7 \\
United Kingdom & 21.8 & 22.1 \\
Germany & 20.3 & 22.2 \\
& & \\
\hline
\end{tabular}

Note: In firms of 10 employees or more.

Source: Eurostat, Labor Force Survey. 


\section{Okun's Law, Cyclical and Structural Unemployment}

\subsection{Okun's Law}

Okun's Law posits a relationship between the cyclical unemployment rate (the difference between the actual unemployment rate and the structural unemployment rate) ${ }^{10}$ and the output gap (the difference between actual output and "potential" output):

$$
u_{t}-u_{t}^{*}=\beta\left(\log Y_{t}^{*}-\log Y_{t}\right)+\epsilon_{t}
$$

where $Y_{t}$ is output, $u_{t}$ is the unemployment rate, and $*$ indicates a long-run level.

The ideas behind Okun's Law are very simple. Employment depends on output, and unemployment depends on employment.

$$
\begin{gathered}
\log L_{t}-\log L_{t}^{*}=\gamma\left(\log Y_{t}-\log Y_{t}^{*}\right)+\eta_{t} \\
u_{t}-u_{t}^{*}=-\delta\left(\log L_{t}-\log L_{t}^{*}\right)+\mu_{t}
\end{gathered}
$$

where $L_{t}$ is employment. Substituting equation (2) in (3) we get (1).

We will slightly change the traditional Okun's law presentation, as we are interested in this paper in the employment rate - the ratio of employment to the working age population-rather than the employment level. Adding and subtracting the log of $N_{t}$ - the working age population - in equations (1)-(3) we get:

$$
\begin{gathered}
u_{t}-u_{t}^{*}=\beta\left(\log \left(\frac{Y_{t}}{N_{t}}\right)^{*}-\log \left(\frac{Y_{t}}{N_{t}}\right)\right)+\epsilon_{t} \\
\log \left(\frac{L_{t}}{N_{t}}\right)-\log \left(\frac{L_{t}}{N_{t}}\right)^{*}=\gamma\left(\log \left(\frac{Y_{t}}{N_{t}}\right)-\log \left(\frac{Y_{t}}{N_{t}}\right)^{*}\right)+\eta_{t} \\
u_{t}-u_{t}^{*}=-\delta\left(\log \left(\frac{L_{t}}{N_{t}}\right)-\log \left(\frac{L_{t}}{N_{t}}\right)^{*}\right)+\mu_{t}
\end{gathered}
$$

Equation (4) shows the link between the cyclical unemployment rate and the output gap, with the output gap now defined as the difference between actual GDP and potential GDP per working age person; equation (5) shows the link between between the output gap and the employment rate; and equation (6) shows the link between the unemployment rate and the employment rate.

Determining the natural rate of unemployment and the level of potential output is a tricky problem. A common approach is to smooth the unemployment and the real GDP series with the Hodrick-Prescott (HP) filter (Ball, Leigh and Loungani, 2013), an approach

\footnotetext{
${ }^{10}$ Cyclical unemployment depends on the business cycle. It will be high during recessions, and fall to zero when output returns to potential. Structural unemployment is unemployment that would exist even when cyclical unemployment is zero. It is due to other factors, such as as high wages, mismatch between labor demand and labor supply, etc.
} 
we will follow in this paper. In line with Ball et al, we use a value of 100 for the $\lambda$ parameter in the HP filter. This results in the the estimates for structural unemployment, potential output growth, and output gaps depicted below. ${ }^{11}$

- Figure 13 shows the breakdown of unemployment into cyclical and structural unemployment. It indicates that much of the changes in unemployment rates in the past 45 years reflect changes in the structural rather than cyclical component.

- Figure 14 shows potential and actual output growth. This suggests that the post 2008 slowdown reflects both a slowdown in headline GDP growth and in potential GDP growth.

- Figure 15 shows the resulting output gaps.

\footnotetext{
${ }^{11}$ We omitted Germany as data were only available from 1990 onwards.
} 
Figure 13. Unemployment Rate: Cyclical and Structural, 1970-2014 (Percent)

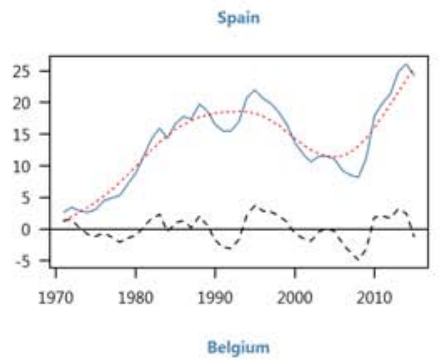

Netherlands
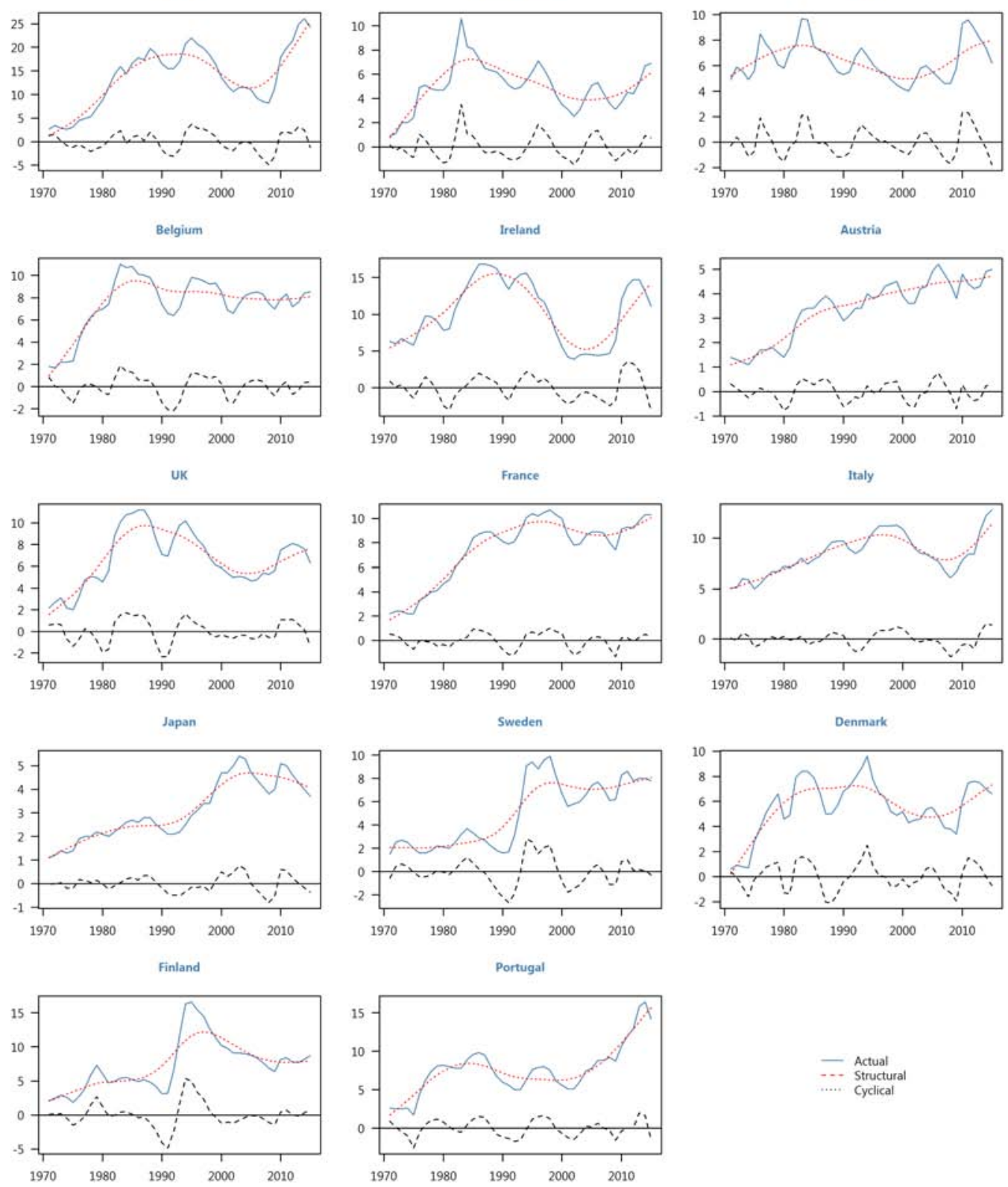
Figure 14. Real GDP Per Working Age Capita Growth: Actual and Potential, 1970-2014

(Percent)
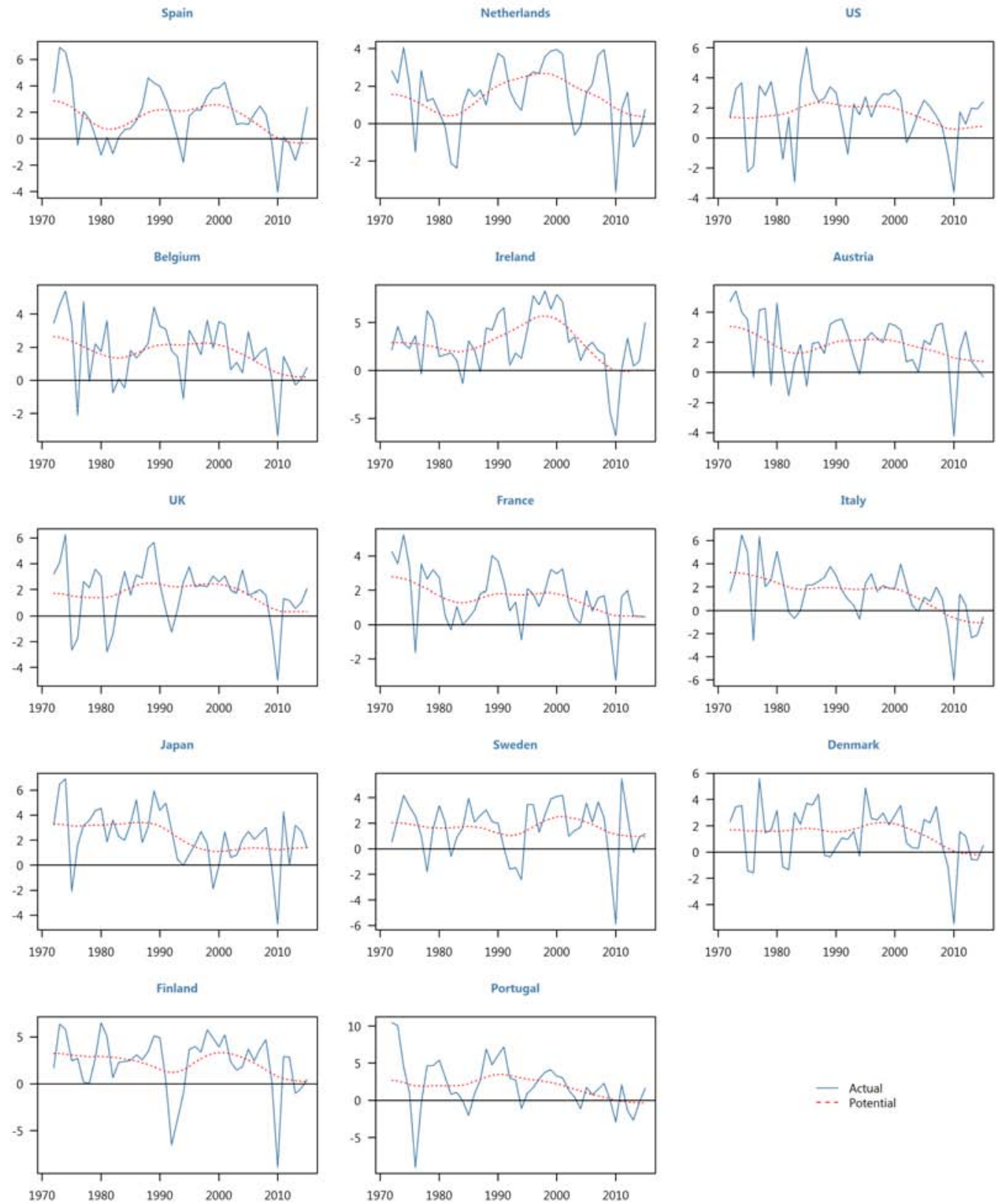
Figure 15. Output Gaps, 1970-2014

$$
\text { (Percent) }
$$
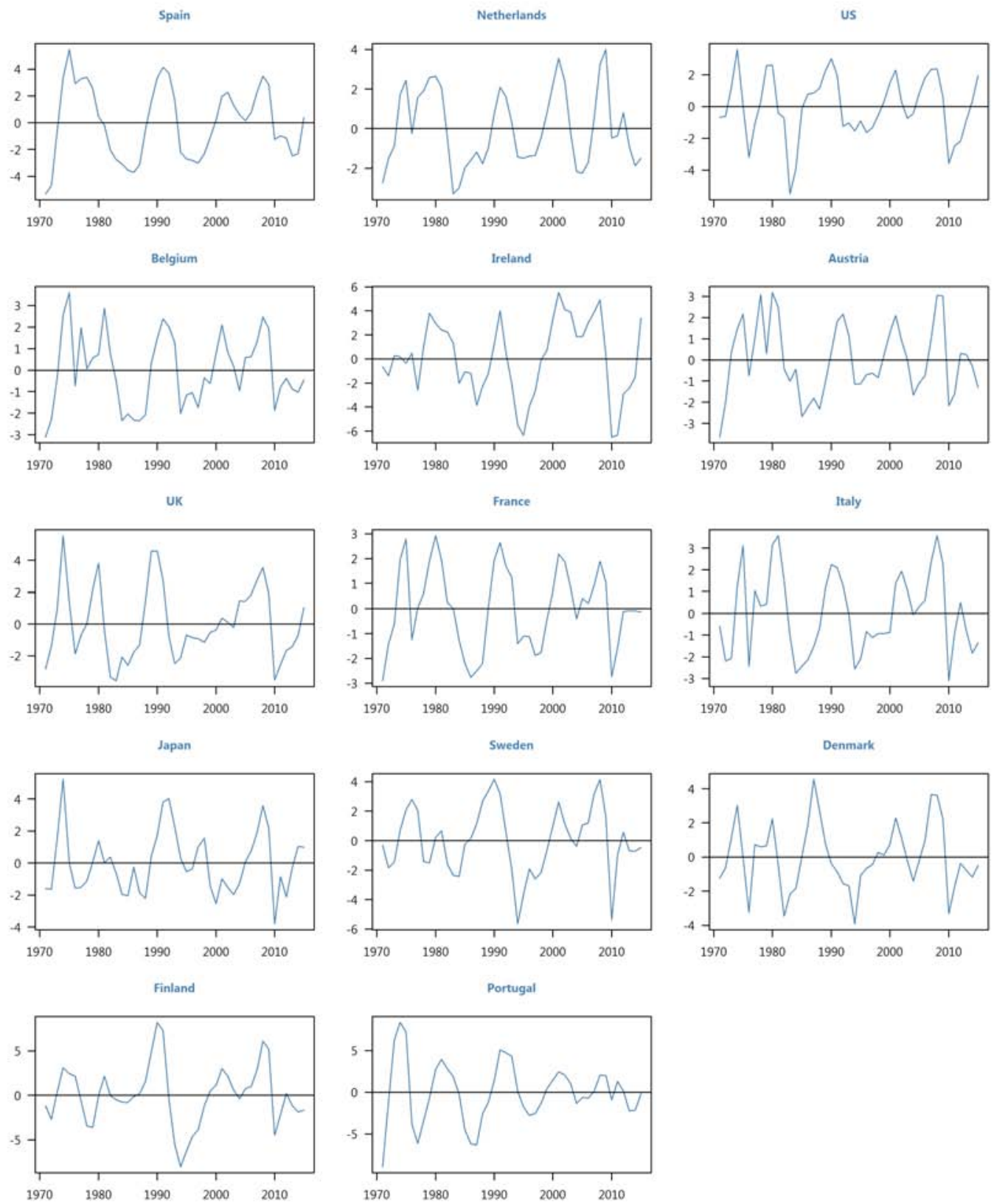


\subsection{Sensitivity Analysis}

The difficulties in determining both the NAIRU and potential GDP are well known. This is true generally but the case of Ireland is a striking example. The estimates of OECD and the EU are markedly different in almost any year in the past 20 years (Figure 16). Also revisions in estimates can be substantial. For Ireland, again, the April 2008 IMF World Economic Outlook (WEO), put 2008 GDP at 0.3 percent above potential; in the latest WEO it is shown at almost 10 percent above potential for the same year (Figure 17).

In terms of the mechanics of using an HP filter, a higher $\lambda$ in the equation produces smaller changes in the NAIRU and potential output growth and larger cyclical effects (Figure 18). As a result a larger part of the changes in unemployment rates is attributed to the output gap and a smaller share to changes in real wages. Nevertheless, as we will show, the role of real wages remains important regardless of the particular parameterization of the HP filter.

We use a $\lambda$ of 100 for a number of reasons:

- It is the standard value for annual data suggested by the literature, following the seminal article by Backus and Kehoe (1992). This value is also implemented as the default value for annual data in econometric software packages such as Eviews ${ }^{12}$ and Matlab. ${ }^{13}$

- The more recent literature suggests that a lower $\lambda$ may be warranted. Ravn and Uhlig (2002) have argued that for annual data a smaller coefficient of 6.25 should be used, as as this results in the same trend as using a $\lambda$ of 1600 for quarterly data - the value typically recommended for such data. If we use a lower $\lambda$ in the HP-filter, swings in output and unemployment gaps are smaller (Figure 18), and the role of real wages becomes more important.

- A high $\lambda$ would suggest that current output gaps are still very large, but we doubt this is the case.

- Martin, Munyan, and Wilson (2015) find that potential output growth tends to get overestimated in recessions, resulting in an overestimation of the output gap. Over time, output gaps close - not because of rapid actual GDP growth, but because potential output growth is revised down.

- The debate on the size of the output gap is similar to that in the 1970s and 1980s. When employment rose sharply in many European countries in the 1970s, initially the idea was that large output gaps had emerged. Over time it became apparent that potential output growth had slowed and that initial estimates of output gaps had been too large.

\footnotetext{
${ }^{12}$ See http://www.eviews.com/help/helpintro.html\#page/EViews $\% 25209 \% 2520 H e l p \% 2$ Fseries. 017. 26.html

${ }^{13}$ See http: //www . mathworks. com/help/econ/hpfilter.html.
} 
Figure 16. Ireland: Output Gap and NAIRU according to OECD and EU

(Percent)

NAIRU
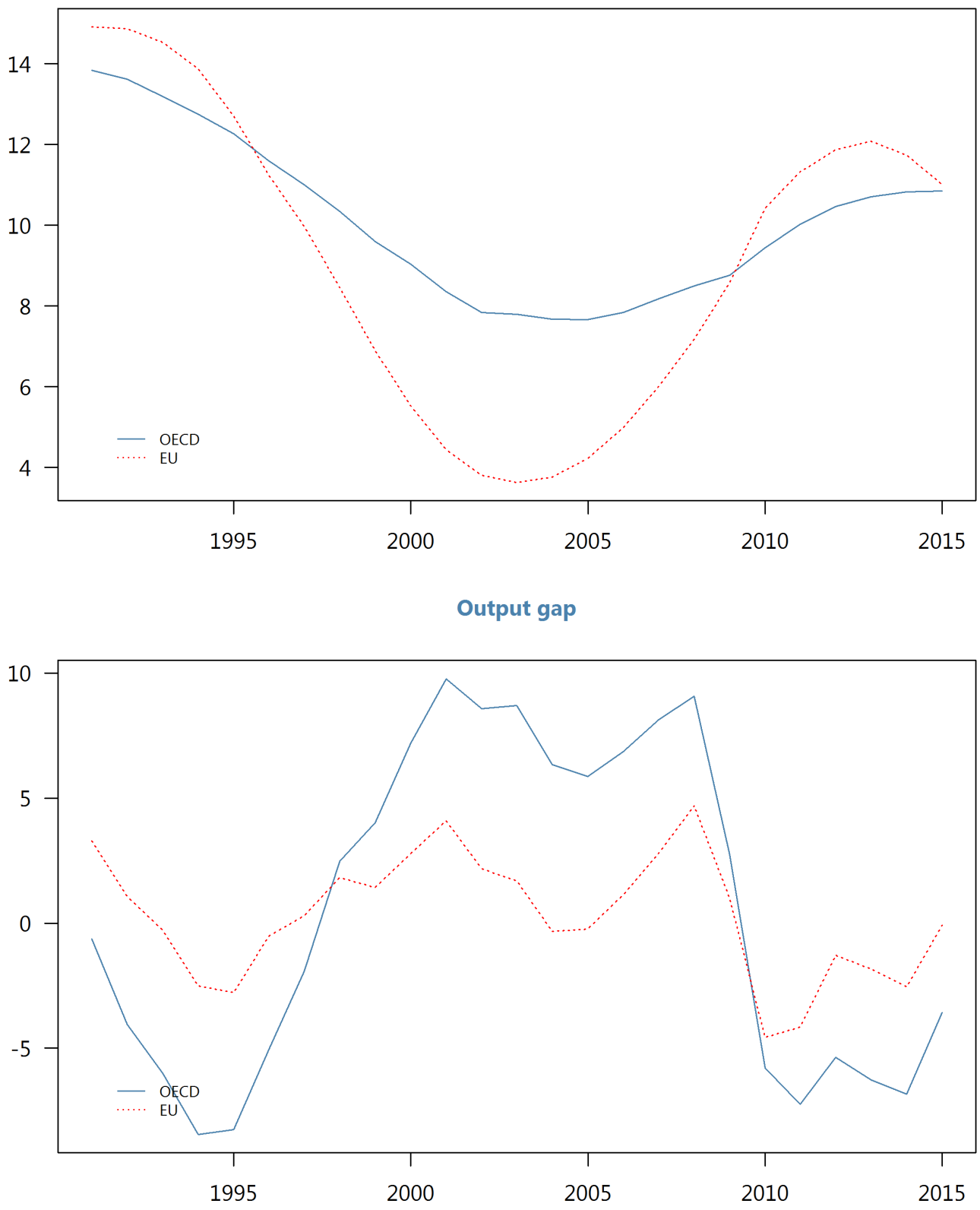
Figure 17: Output Gap Estimates according to various IMF WEO Vintages (Percent)
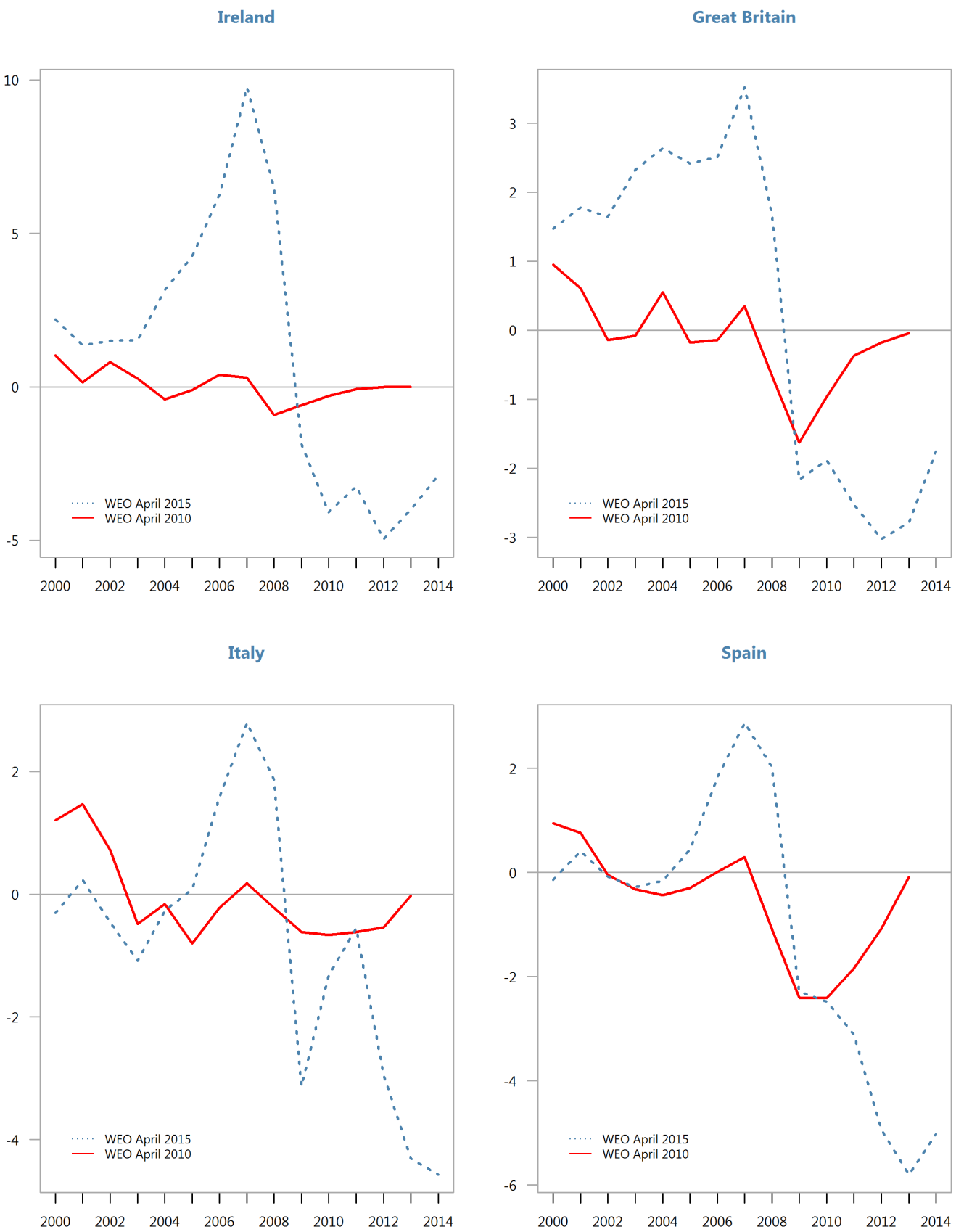
Figure 18: Spain: Impact of lambda in HP-Filter
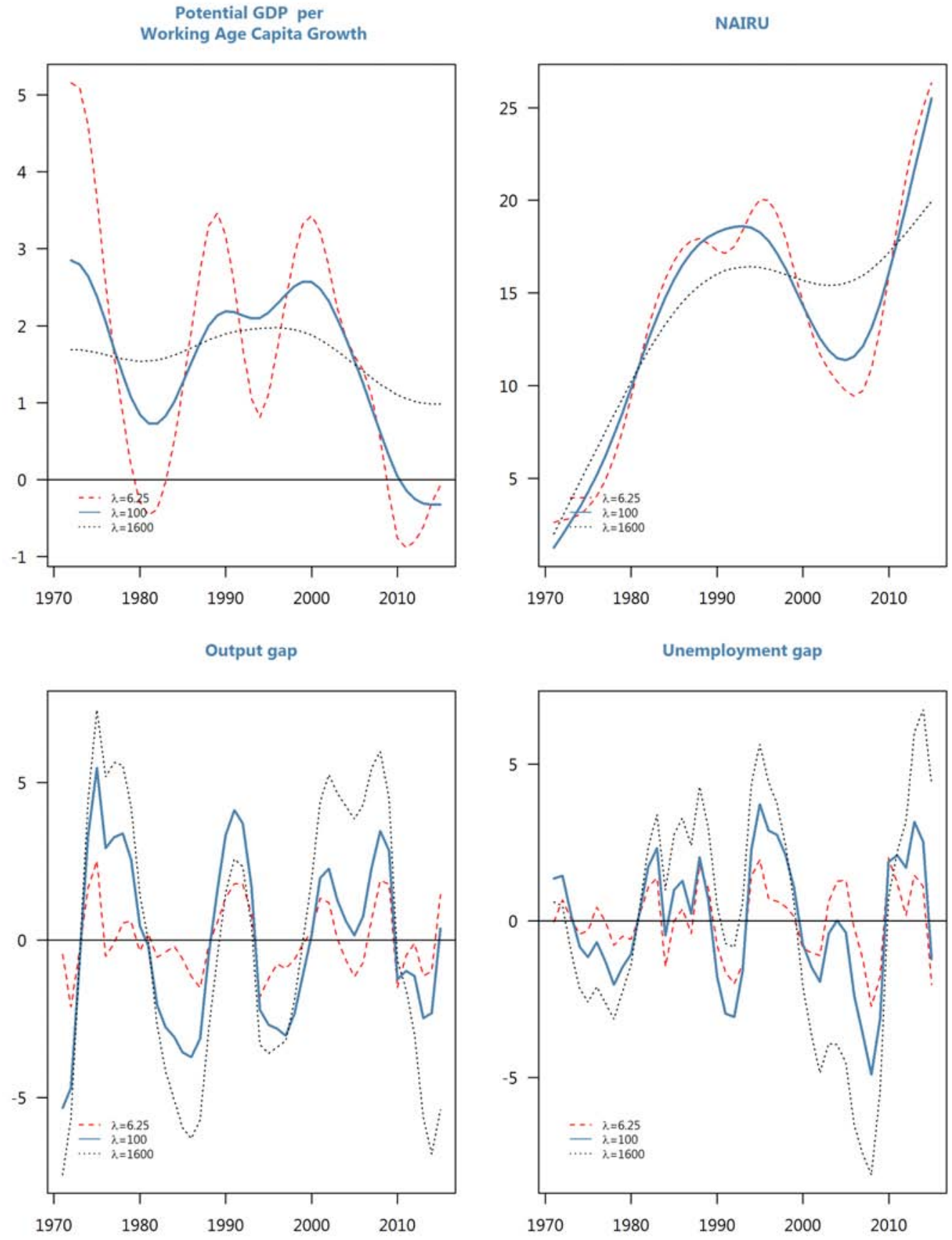


\section{The Output Gap and Unemployment}

\subsection{The Output Gap and Cyclical Unemployment}

In line with Okun's Law, a substantial part of cyclical unemployment is explained well by movements in the output gap. We estimated equation (4) for 14 advanced countries, using annual Ameco data for 1970-2014. The results are in Table 2. The output gap is significant for all countries, although the coefficient differs across countries, a result also found by Ball, Leigh and Loungani (2013). This confirms that there is indeed a close correlation between the output gap and the cyclical unemployment rate.

Output developments, however, generally fail to explain a large part of the movements in the overall unemployment rate. More formally, if we regress the aggregate unemployment rate on the output gap:

$$
u_{t}=\beta\left(\log \left(\frac{Y_{t}}{N_{t}}\right)-\log \left(\frac{Y_{t}}{N_{t}}\right)^{*}\right)+\epsilon_{t}
$$

we get indeed a much weaker relationship with far lower $R^{2}$ (Table 3 ).

Casual observation suggests that for some countries the correlation between the output gap and the overall unemployment rate is not very strong. In Spain, for example, there has been a very close link between the output gap and the unemployment gap, but the output gap explains only a small part of changes in the unemployment rate in the last forty-five years (Figure 19). It would appear, therefore, that there are other factors at work. 
Table 2: Regression of Unemployment Gap on Output Gap, 1970-2014

\begin{tabular}{rrrr}
\hline & output gap & t-value & R2 $($ adj $)$ \\
\hline AUT & -0.15 & -5.69 & 0.42 \\
BEL & -0.38 & -6.02 & 0.45 \\
DNK & -0.43 & -7.57 & 0.56 \\
ESP & -0.60 & -8.44 & 0.61 \\
FIN & -0.48 & -12.00 & 0.76 \\
FRA & -0.30 & -8.62 & 0.62 \\
GBR & -0.35 & -7.38 & 0.55 \\
IRL & -0.46 & -11.26 & 0.74 \\
ITA & -0.14 & -2.47 & 0.10 \\
JPN & -0.14 & -8.41 & 0.61 \\
NLD & -0.37 & -6.62 & 0.49 \\
PRT & -0.21 & -6.38 & 0.47 \\
SWE & -0.40 & -8.02 & 0.59 \\
USA & -0.50 & -14.44 & 0.83 \\
\hline
\end{tabular}

Table 3: Regression of Unemployment Rate on Output Gap, 1970-2014

\begin{tabular}{rrrr}
\hline & output gap & t-value & R2 (adj) \\
\hline AUT & -0.18 & -1.67 & 0.04 \\
BEL & -0.44 & -2.09 & 0.07 \\
DNK & -0.55 & -3.63 & 0.22 \\
ESP & -0.98 & -2.92 & 0.15 \\
FIN & -0.64 & -4.61 & 0.32 \\
FRA & -0.39 & -1.61 & 0.04 \\
GBR & -0.47 & -3.00 & 0.15 \\
IRL & -0.88 & -5.45 & 0.39 \\
ITA & -0.29 & -1.84 & 0.05 \\
JPN & -0.19 & -2.01 & 0.06 \\
NLD & -0.48 & -3.53 & 0.21 \\
PRT & -0.28 & -2.13 & 0.07 \\
SWE & -0.53 & -3.03 & 0.16 \\
USA & -0.58 & -7.35 & 0.55 \\
\hline
\end{tabular}


Figure 19. Spain: Output Gap and Unemployment, 1970-2014

(Percent)

Output Gap and Unemployment Gap

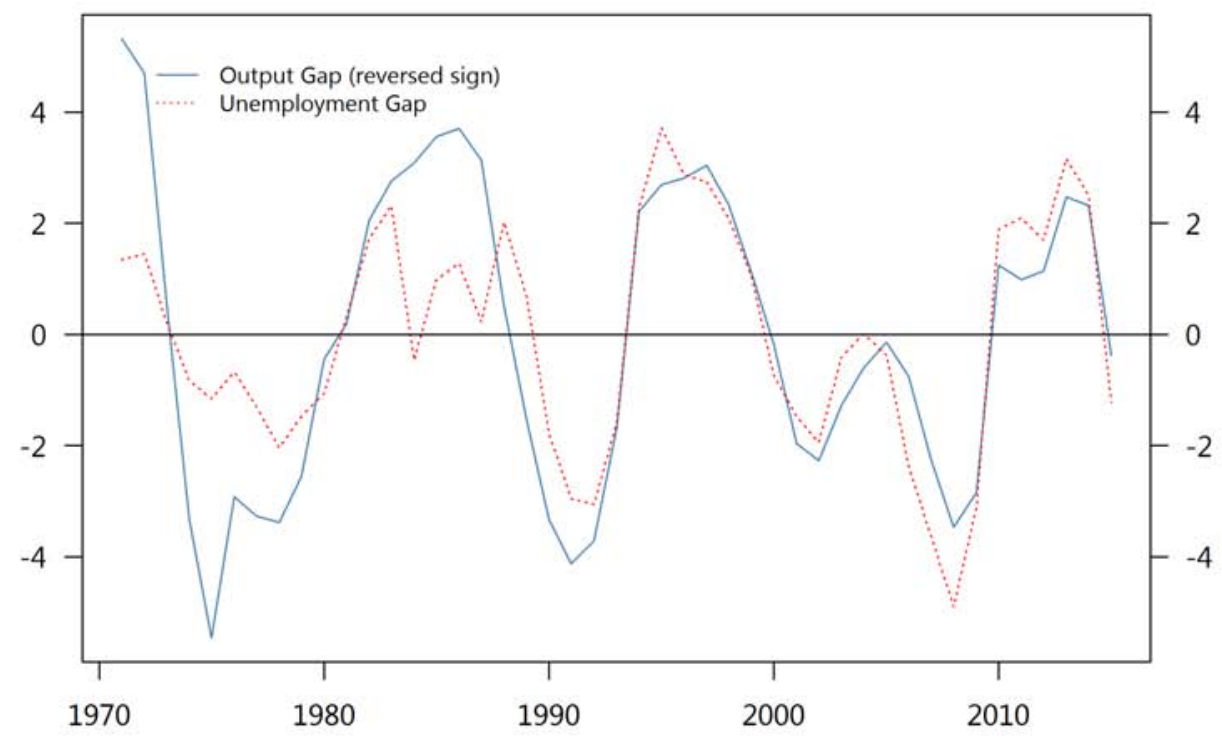

Output Gap and Unemployment Rate

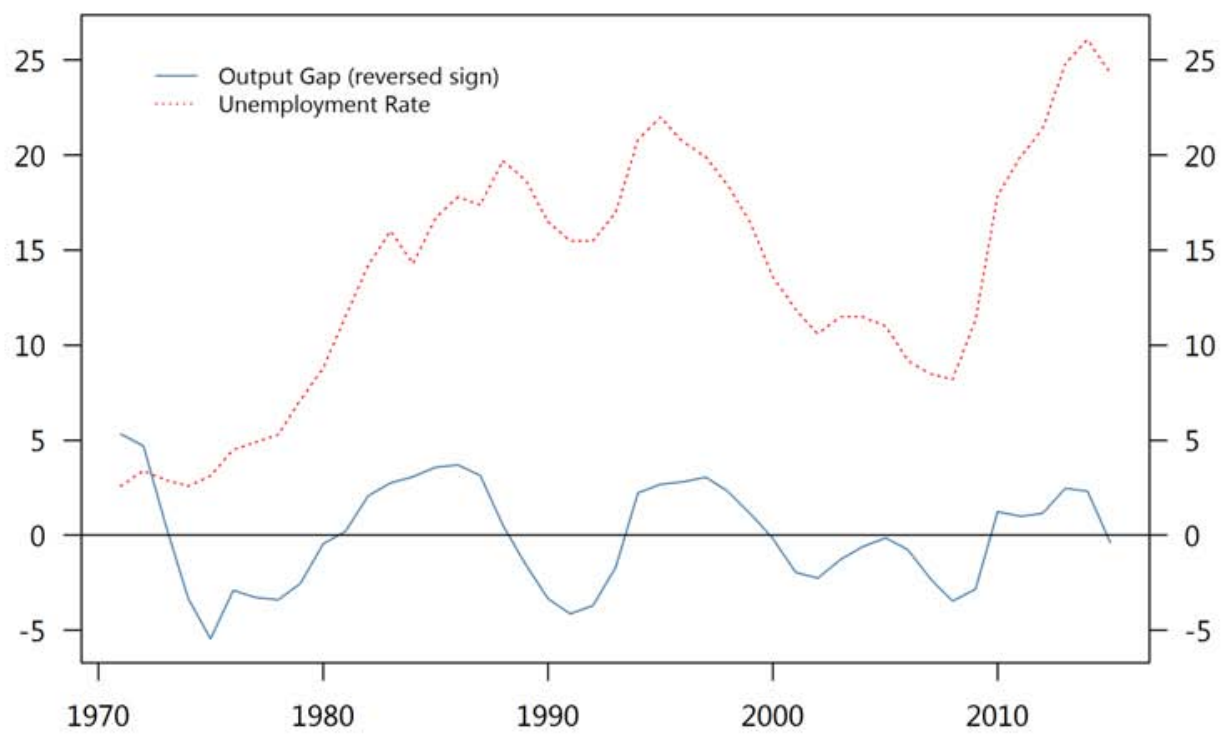




\section{The Output Gap and the Employment Gap and Overall Employment}

Movements in employment rates - that is, the ratio of employment to working age population - are often more informative than changes in unemployment. This is true for comparisons in one country over time. For example, in the Netherlands, the unemployment rate in 2014 (6.9 percent) was virtually the same as in 1995 (7.1 percent), but the employment to working age population rate in 2014 was almost 10 percentage points higher. Employment ratios are also often more informative than unemployment rates for comparisons between countries.

Using employment rather than unemployment rates has another advantage: using production functions, we can develop a straightforward relationship between output, wages and the employment rate. To go from here to an unemployment rate would require us to develop a labor supply equation, which is far from straightforward.

As with the unemployment rate, we assume that the employment rate consists of two parts: cyclical employment and structural employment.

$$
\log \left(\frac{L_{t}}{N_{t}}\right)=\log \left(\frac{L_{t}}{N_{t}}\right)^{*}+\log \left(\frac{L_{t}}{N_{t}}\right)^{c}
$$

where $L_{t}$ denotes employment, and $N_{t}$ the working age population.

Equation (5) links the "employment rate gap" to the output gap:

$$
\log \left(\frac{L_{t}}{N_{t}}\right)-\log \left(\frac{L_{t}}{N_{t}}\right)^{*}=\gamma\left(\log \left(\frac{Y_{t}}{N_{t}}\right)-\log \left(\frac{Y_{t}}{N_{t}}\right)^{*}\right)+\eta_{t}
$$

We estimated equation (9) for the same countries and time period. The results are in Table 4. The fit is fairly good. Also, the coefficients are somewhat higher than for the unemployment rate, which is to be expected, as a drop in employment during downturns is likely to lead to a rise of "discouraged workers" who drop out of the labor force, muting the effect on the unemployment rate. But the overall picture is not very different. 
Table 4: Regression of Employment Gap on Output Gap, 1970-2014

\begin{tabular}{rrrr}
\hline & output gap & t-value & R2 (adj) \\
\hline AUT & 0.51 & 8.98 & 0.64 \\
BEL & 0.55 & 9.13 & 0.65 \\
DNK & 0.56 & 7.38 & 0.55 \\
ESP & 1.05 & 14.81 & 0.83 \\
FIN & 0.75 & 12.03 & 0.77 \\
FRA & 0.52 & 10.39 & 0.71 \\
GBR & 0.57 & 6.82 & 0.51 \\
IRL & 0.73 & 9.82 & 0.68 \\
ITA & 0.49 & 6.04 & 0.45 \\
JPN & 0.24 & 3.48 & 0.20 \\
NLD & 0.55 & 7.67 & 0.57 \\
PRT & 0.48 & 11.13 & 0.74 \\
SWE & 0.61 & 6.90 & 0.51 \\
USA & 0.64 & 11.37 & 0.74 \\
\hline
\end{tabular}

Table 5: Regression of Employment Rate on Output Gap, 1970-2014

\begin{tabular}{rrrr}
\hline & output gap & t-value & R2 (adj) \\
\hline AUT & 0.67 & 2.43 & 0.10 \\
BEL & 0.81 & 2.10 & 0.07 \\
DNK & 0.71 & 5.72 & 0.42 \\
ESP & 1.64 & 3.15 & 0.17 \\
FIN & 1.04 & 4.30 & 0.28 \\
FRA & 0.73 & 2.87 & 0.14 \\
GBR & 0.72 & 3.94 & 0.25 \\
IRL & 1.45 & 3.87 & 0.24 \\
ITA & 0.79 & 2.21 & 0.08 \\
JPN & 0.28 & 1.34 & 0.02 \\
NLD & 0.92 & 1.28 & 0.01 \\
PRT & 0.61 & 1.93 & 0.06 \\
SWE & 0.77 & 3.19 & 0.17 \\
USA & 0.75 & 2.20 & 0.08 \\
\hline
\end{tabular}


As with the unemployment rate, however, the relationship between the output gap and the overall employment rate is much weaker. This is apparent from casual observation: Figure 20 shows that in Spain, for example, the "employment gap" has moved in line with the output gap, but the employment gap is only a small part of the change in the employment rate. It is confirmed more generally by regressing the employment rate on the output gap:

$$
\log \left(\frac{L_{t}}{N_{t}}\right)=\gamma\left(\log \left(\frac{Y_{t}}{N_{t}}\right)-\log \left(\frac{Y_{t}}{N_{t}}\right)^{*}\right)+\eta_{t}
$$

The results are in Table 5. Comparing Table 5 with Table 4, we see that the link is indeed much weaker. It appears therefore that in some countries, much of the change in the employment rate in the past forty five years has been structural rather than cyclical (Figure 21). This raises the question of the role of wages in structural employment 
Figure 20. Spain: Output Gap and Employment Rate, 1970-2014

(Percent)

Output Gap and Employment Gap

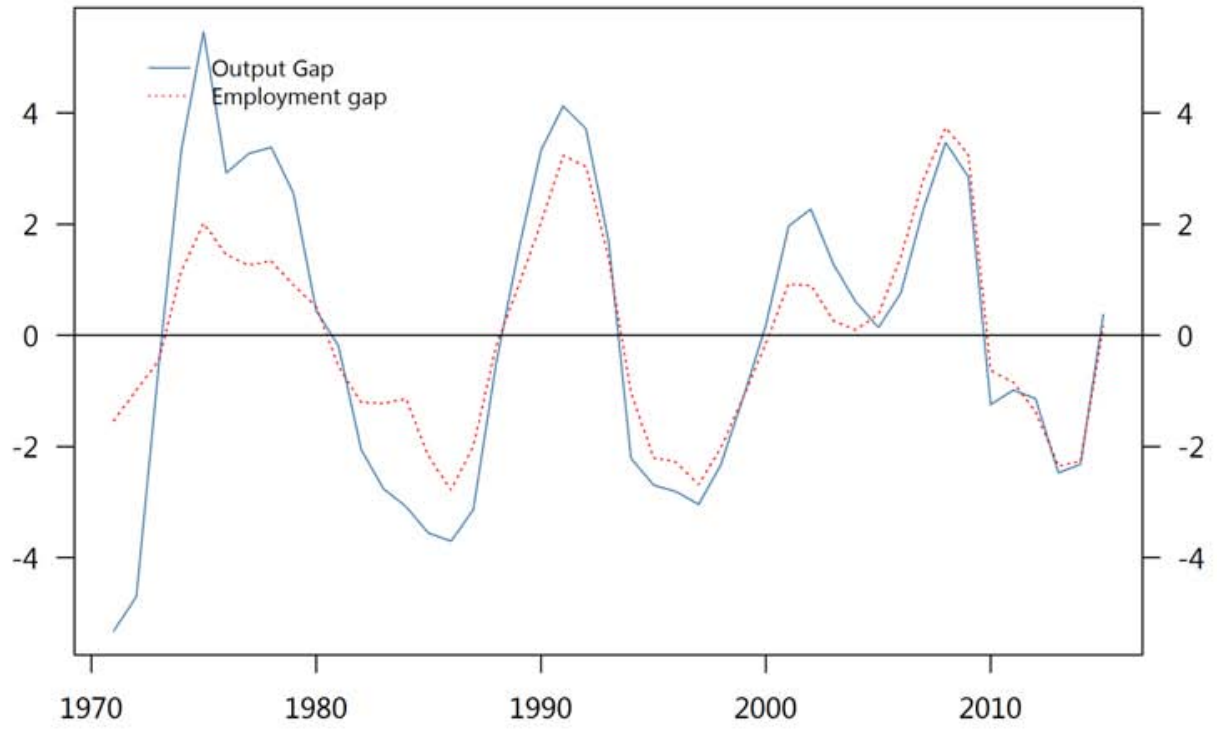

Output Gap and Employment Rate

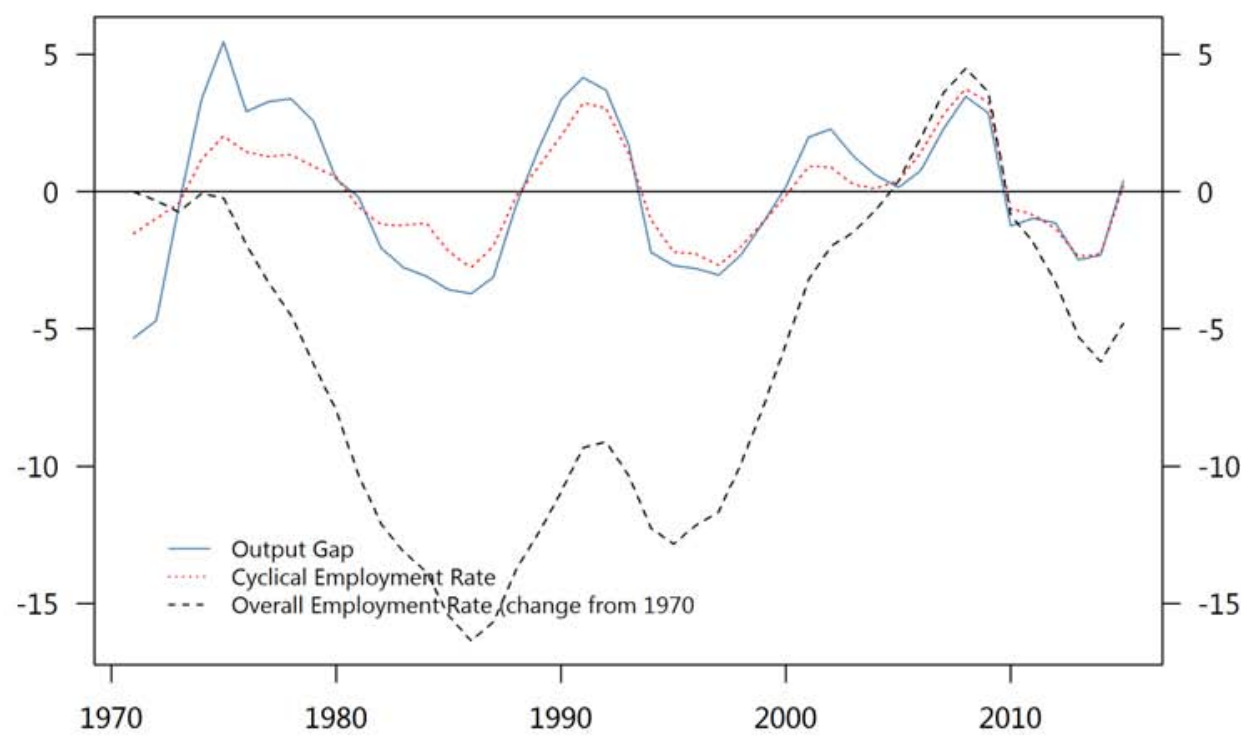


Figure 21. Employment Rate: Actual and Structural, 1970-2014 (Percent)
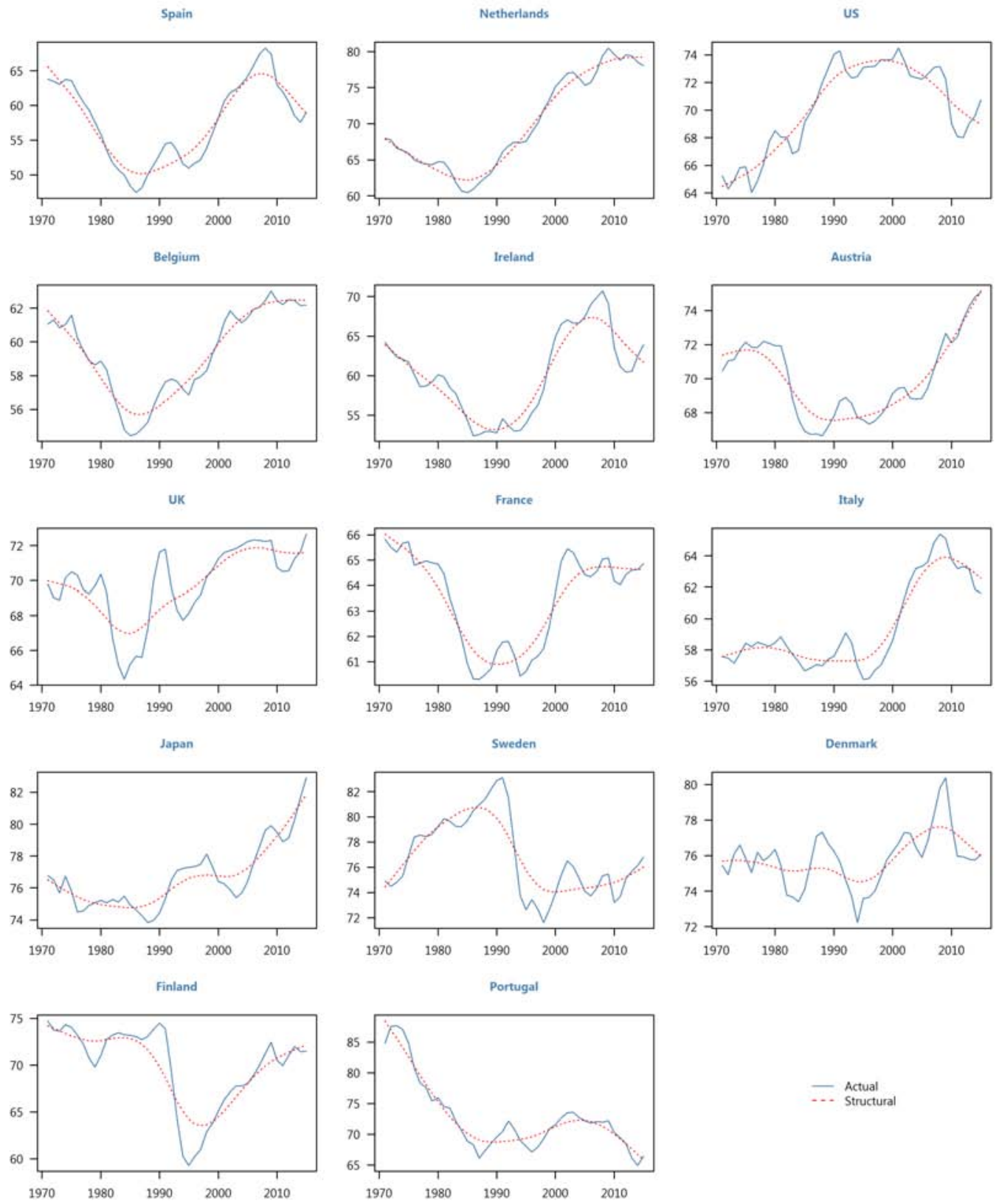


\section{Real Wages and the Structural Employment Rate}

Consider a framework where, in the medium term when the output gap and thus cyclical (un)employment is zero, there is a negative link between real wages and the employment rate.

\subsection{The Framework}

The employment to working age population rate can be written as the ratio of GDP per working age capita to labor productivity (i.e., GDP per worker):

$$
\frac{L_{t}}{N_{t}}=\frac{\frac{Y_{t}}{N_{t}}}{\frac{Y_{t}}{L_{t}}}
$$

This shows that if labor productivity rises faster than GDP per working age capita, the employment rate will fall, while if it rises less fast, the employment rate will rise.

What would make labor productivity rise faster than GDP per working age capita? A likely candidate is that wages are growing "too fast". To see this, note that labor productivity can rise for two reasons: because of labor-augmenting technological progress, or because firms replace labor by capital in reaction to an increase in the relative price of labor.

- If labor-productivity rises because of labor-augmenting technological progress, it is likely that the increase in labor productivity will also lead to an increase in GDP per working age capita, and employment is likely to be relatively unaffected.

- By contrast, if labor productivity rises becauses firms - in reaction to an increase in the relative price of labor - substitute capital for labor, GDP per working age capita will not increase, and the employment rate will fall.

How do we determine whether wages grow too fast? What matters in is not the growth rate of real wages itself, but the growth rate of real wages relative to technological progress. If wages grow in line with labor-augmenting technological progress, the cost of labor will remain unchanged, and firms will not change the capital-labor mix. By contrast, if wages grow faster than technology, then firms will change the mix, and boost labor productivity growth beyond technological progress.

To show this more formally, assume that output is exogenous and increases at rate $\gamma+n$, where $\gamma$ is the rate of technological progress, and $n$ the growth rate of the working age population.

$$
Y_{t}=Y_{0} e^{(\gamma+n) t}
$$


The assumption that output is exogenous is not as restrictive as it seems. We are interested in changes employment rate which, as we will show, depends on wage growth relative to GDP growth - not on GDP growth or wage growth itself.

We assume that the production technology is a normalized CES production function with labor-augmenting technological progress. With marginal productivity of labor equal to the real wage, we can deduce that labor productivity is equal to (see Annex 1): ${ }^{14}$

$$
\frac{Y_{t}}{L_{t}}=\left(\frac{Y_{0}}{L_{0}}\right) e^{\gamma t}\left(\frac{W_{t}}{e^{\gamma_{t}} W_{0}}\right)^{\beta}
$$

Taking logs and differences we get:

$$
\Delta \log \left(\frac{Y_{t}}{L_{t}}\right)=\gamma+\beta\left(\Delta \log W_{t}-\gamma\right)
$$

which we can rewrite as

$$
\Delta \log L_{t}=\Delta \log Y_{t}-\gamma-\beta\left(\Delta \log W_{t}-\gamma\right)
$$

Substituting equation (12) in equation (15) we get:

$$
\Delta \log L_{t}=n-\beta\left(\Delta \log W_{t}-\gamma\right)
$$

It can easily be checked that if wages grow at rate $\gamma$ :

- Employment will grow at rate $n$ (see equation (16)). In other words, the employment rate will stay constant.

- Labor productivity will grow at rate $\gamma$ - the rate of technological progress (see equation (14)).

- The wage share will remain constant (from equation (13); see Annex 2).

To interpret equation (16), note that

$$
\begin{gathered}
\gamma=\Delta \log \left(\frac{Y_{t}}{N_{t}}\right) \\
n=\Delta \log N_{t}
\end{gathered}
$$

Substituting equation (17) and (18) in (16) we get:

$$
\Delta \log \left(\frac{L_{t}}{N_{t}}\right)=-\beta\left(\Delta \log W_{t}-\Delta \log \left(\frac{Y_{t}}{N_{t}}\right)\right)
$$

\footnotetext{
${ }^{14}$ If we assume that capital-augmenting technological progress grows at the same rate as labor-augmenting technological progress, $\gamma$ is also equal to the growth rate of TFP. See Annex 1.
} 
This shows that the change of the employment rate depends on how much wages grow relative to GDP per working age capita. Integrating equation (19) we get:

$$
\log \left(\frac{L_{t}}{N_{t}}\right)=A-\beta \log \left(\frac{W_{t}}{\frac{Y_{t}}{N_{t}}}\right)
$$

Equation (20) shows that the higher real wages are relative to GDP per working age capita, the lower the employment rate.

Note that we can use equation (20) to reproduce the "wage gap" advocated by Bruno and Sachs (1979, 1985), Lipschitz and Schadler (1984), and Sachs (1983). Assume $L^{F}$ is the level of employment equivalent with full employment, and $W^{F}$ the wage level consistent with full employment. From equation (20) it follows that:

$$
\log \left(\frac{L_{t}^{F}}{N_{t}}\right)=A-\beta \log \left(\frac{W_{t}^{F}}{\frac{Y_{t}}{N_{t}}}\right)
$$

Subtracting equation (21) from equation (20) we get:

$$
\log \left(\frac{L_{t}}{L_{t}^{F}}\right)=-\beta \log \left(\frac{W_{t}}{W_{t}^{F}}\right)
$$

This shows that if real wages are too too high, employment will be below the full employment level.

We will make one further modification. We have derived equation (20) under the assumption that employment depends only on real wages. In practice, this is the case only when the output gap is zero, i.e. when output is at potential. In other words, equation (20) is not a relationship between the actual employment rate and wages relative to actual GDP per working age capita, but between the structural employment rate and wages relative to potential GDP per working age capita.

$$
\log \left(\frac{L_{t}}{N_{t}}\right)^{*}=A-\beta \log \left(\frac{W_{t}}{\left(\frac{Y_{t}}{N_{t}}\right)^{*}}\right)
$$

where $\left(\frac{L_{t}}{N_{t}}\right)^{*}$ is the structural employment rate, and $\left(\frac{Y_{t}}{N_{t}}\right)^{*}$ is potential GDP per working age capita.

We show in Annex 3 that the negative link between average real wage and the employment rate is not the result of changes in the wage share. If we use a Cobb-Douglas production function, we get a similar, negative, link - even though the wage share remains constant by assumption. 


\subsection{Interpretation of the Wage Pressure Variable}

The wage pressure variable is

$$
\frac{W_{t}}{\left(\frac{Y_{t}}{N_{t}}\right)^{*}}
$$

We can rewrite this as:

$$
\left(\frac{W_{t} L_{t}}{Y_{t}}\right)\left(\frac{\frac{\left(\frac{Y_{t}}{N_{t}}\right)}{\left(\frac{Y_{t}}{N_{t}}\right)^{*}}}{\frac{L_{t}}{N_{t}}}\right)
$$

It can be easily checked that equation (25) shows the following expression:

$$
\text { wage share } *\left(\frac{1+\text { output gap }}{\text { employment rate }}\right)
$$

Our variable is thus similar to to the wage share, but "corrected" for the output gap and the employment rate. What is the intuition behind this?

- In many countries, the wage share tends to rise during recessions, and fall during booms. By multiplying the wage share by $(1+$ output gap $)$ we get a "cyclically adjusted" wage share.

- Even after adjusting for the cycle, the wage share itself does not always give a good indication whether wages are a problem. By firing enough workers, firms may keep the wage share low, but at the expense of a low employment rate. By "correcting" the wage share for the employment rate, we get a better impression of whether wages are an issue.

\subsection{Econometrics}

Figure 22 shows that in many countries there is indeed a close link between the ratio of average real wages to potential GDP per working age capita and the structural employment rate. In Spain, for example, the real wage variable seems to explain the drop in the structural employment rate in the 1970 s, the increase in the structural employment rate in the 1990s and 2000s, and the decline in the structural employment rate since $2007 .{ }^{15}$

We estimated equation (23) for 14 advanced countries during the 1970-2014 period (Table 6). For most countries, the real wage coefficient is highly significant and $R^{2}$ high. ${ }^{16}$

\footnotetext{
${ }^{15}$ The decline in the structural employment rate in the United States does not reflect an increase in the structural unemployment rate, but a decline in the labor force participation rate. A debate is ongoing as
} 
Figure 22. Real Wage To Potential GDP Per Working Age Capita Ratio and Structural Employment Rate

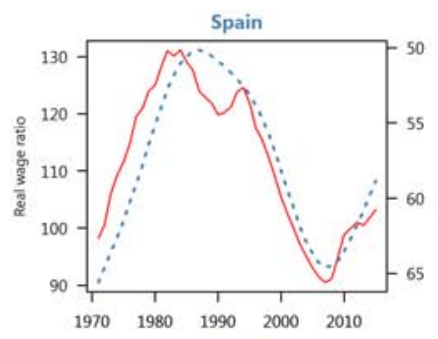
(Percent)
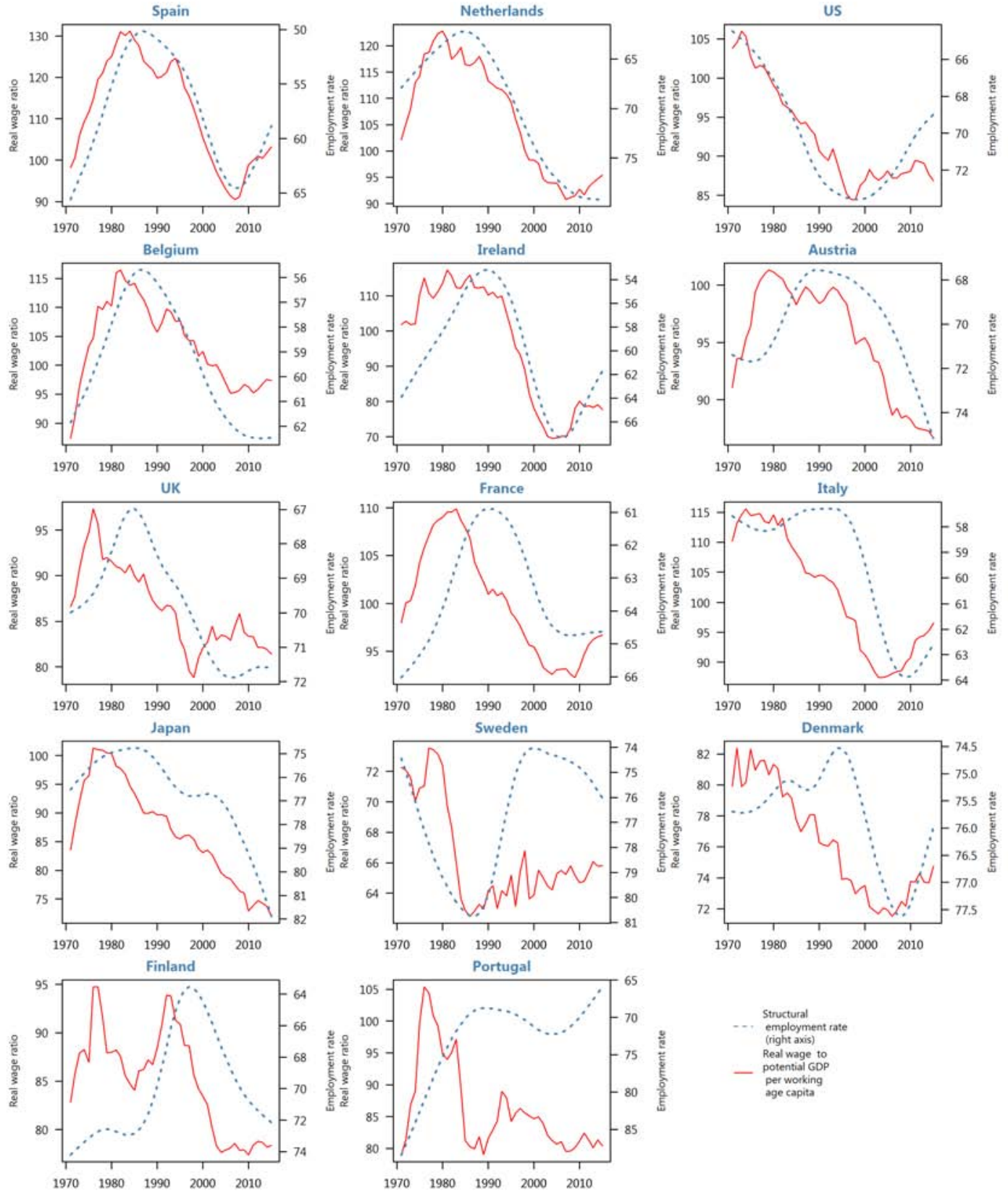
Table 6: Regression of Structural Employment Rate on Real Wage to Potential Real GDP per Working Age Capita, 1970-2014

\begin{tabular}{rrrr}
\hline & real wages & t-value & R2 $($ adj $)$ \\
\hline AUT & -0.37 & -5.39 & 0.39 \\
BEL & -0.51 & -12.37 & 0.78 \\
DNK & -0.14 & -3.98 & 0.25 \\
ESP & -0.69 & -12.80 & 0.79 \\
FIN & 0.00 & 0.01 & -0.02 \\
FRA & -0.13 & -1.95 & 0.06 \\
GBR & -0.29 & -5.37 & 0.39 \\
IRL & -0.34 & -9.44 & 0.67 \\
ITA & -0.33 & -7.78 & 0.57 \\
JPN & -0.21 & -13.14 & 0.80 \\
NLD & -0.84 & -26.23 & 0.94 \\
PRT & 0.40 & 3.21 & 0.17 \\
SWE & -0.01 & -0.13 & -0.02 \\
USA & -0.58 & -14.52 & 0.83 \\
\hline
\end{tabular}

the extent to which the drop in the participation rate is temporary or permanent.

${ }^{16}$ For Finland and Sweden, real wages are not significant; we suspect this reflects the impact of the banking crises in the early 1990s, which led to a sharp drop in employment. For Portugal, real wages have the wrong sign. We suspect this it may the influx of the "retornados" - from May 1974 to the end of the 1970s, as much as a million Portuguese citizens (12 percent of Portugal's population in 1973) returned from Portugal's colonies as destitute refugees - which led to a sharp drop in the employment rate. 


\section{The Relationship between the Overall Employment Rate, Output Gap and Real Wages}

\subsection{The Framework}

We showed in section 3 that

$$
\log \left(\frac{L_{t}}{N_{t}}\right)-\log \left(\frac{L_{t}}{N_{t}}\right)^{*}=\gamma\left(\log \left(\frac{Y_{t}}{N_{t}}\right)-\log \left(\frac{Y_{t}}{N_{t}}\right)^{*}\right)+\eta_{t}
$$

and in section 6 that

$$
\log \left(\frac{L_{t}}{N_{t}}\right)^{*}=A-\beta \log \left(\frac{W_{t}}{\left(\frac{Y_{t}}{N_{t}}\right)^{*}}\right)
$$

Combining equations (27) and (28) we get an equation for the overall employment rate:

$$
\log \left(\frac{L_{t}}{N_{t}}\right)=A-\beta \log \left(\frac{W}{\left(\frac{Y_{t}}{N_{t}}\right)^{*}}\right)+\gamma\left(\log \left(\frac{Y_{t}}{N_{t}}\right)-\log \left(\frac{Y_{t}}{N_{t}}\right)^{*}\right)+\eta_{t}
$$

What is the interpretation of equation (29)?

- In the medium term, when the output gap is zero, the employment rate depends only on the ratio of average real wages to potential GDP per working age capita.

- In the short run, when output can deviate from potential, the employment rate also depends on the output gap.

This framework is not only similar to the frameworks developed in the early 1980s discussed in section 1. It also seems in line with new Keynesian frameworks, where in the medium-term demand has no impact on employment, and employment is determined by factors such as the strength of the unions, with stronger unions increasing wages and reducing employment.

\subsection{Econometric Analysis}

How do we determine the coefficients for equation (29)?

- One possibility is to use the regression coefficients of Table 4 (for $\alpha$ ) and Table 6 for $\gamma$. The results are in Table 7 .

- Another possibility is to econometrically estimate equation (29). The results are in Table $8 .^{17}$ 
Table 7: Employment Rate Regression Coefficients obtained from Separate Regressions

\begin{tabular}{rrrrr}
\hline & Output gap & t-value & Real wages & t-value \\
\hline AUT & 0.51 & 8.98 & -0.37 & -5.39 \\
BEL & 0.55 & 9.13 & -0.51 & -12.37 \\
DNK & 0.56 & 7.38 & -0.14 & -3.98 \\
ESP & 1.05 & 14.81 & -0.69 & -12.80 \\
FIN & 0.75 & 12.03 & 0.00 & 0.01 \\
FRA & 0.52 & 10.39 & -0.13 & -1.95 \\
GBR & 0.57 & 6.82 & -0.29 & -5.37 \\
IRL & 0.73 & 9.82 & -0.34 & -9.44 \\
ITA & 0.49 & 6.04 & -0.33 & -7.78 \\
JPN & 0.24 & 3.48 & -0.21 & -13.14 \\
NLD & 0.55 & 7.67 & -0.84 & -26.23 \\
PRT & 0.48 & 11.13 & 0.40 & 3.21 \\
SWE & 0.61 & 6.90 & -0.01 & -0.13 \\
USA & 0.64 & 11.37 & -0.58 & -14.52 \\
\hline
\end{tabular}

Table 8: Regression of Employment Rate on Output Gap and Real Wage to Potential GDP per Working Age Capita, 1970-2014

\begin{tabular}{rrrrrr}
\hline & output gap & t-value & real wages & t-value & R2 (adj) \\
\hline AUT & 0.79 & 3.51 & -0.36 & -4.87 & 0.41 \\
BEL & 0.97 & 5.76 & -0.54 & -13.43 & 0.82 \\
DNK & 0.69 & 5.78 & -0.12 & -2.39 & 0.48 \\
ESP & 1.22 & 5.12 & -0.72 & -12.92 & 0.83 \\
FIN & 1.04 & 4.19 & 0.01 & 0.05 & 0.27 \\
FRA & 0.73 & 2.99 & -0.14 & -1.94 & 0.19 \\
GBR & 0.76 & 5.00 & -0.30 & -4.41 & 0.47 \\
IRL & 0.96 & 3.96 & -0.33 & -8.22 & 0.70 \\
ITA & 0.69 & 2.77 & -0.33 & -6.85 & 0.56 \\
JPN & 0.32 & 2.75 & -0.22 & -9.81 & 0.69 \\
NLD & 0.87 & 5.13 & -0.85 & -27.06 & 0.95 \\
PRT & 0.47 & 1.62 & 0.39 & 3.02 & 0.21 \\
SWE & 0.77 & 3.15 & -0.02 & -0.17 & 0.15 \\
USA & 0.79 & 5.69 & -0.59 & -14.67 & 0.85 \\
\hline
\end{tabular}


The two methods produce very similar coefficients for real wages. The second method yields higher coefficients for the output gap. In order not to to downplay the importance of the output gap we therefore opt for the second method.

For most countries, both the output gap and real wages matter: the output gap is significant in all but one country, while real wages are significant in all but three countries. ${ }^{18}$. In Spain, for example, a 1 percentage point increase in the output gap leads to a drop in the employment rate by 1.2 percent. By comparison, a 1 percentage point fall in the real wage to potential GDP per working age capita boosts the employment rate by 0.7 percent.

In section 4 we had shown that the output gap did not have much explanatory power for the overall employment rate (in contrast with the cyclical employment rate). Adding real wages to the employment rate equation significantly adds to the explanatory power, as can be seen by comparing Tables 5 and 8 - see Table 9 .

While real wages have significant explanatory power in explaining the employment rate they do not help explain the employment gap (Table 10). This further confirms that real wages matter for employment because they influence structural employment-not cyclical employment.

\subsection{Application to Spain and the United Kingdom}

We can use the econometric model to show the importance of real wages (Figure 23). This confirms that in Spain, real wages exacerbated the employment losses, while in the United Kingdom real wages mitigated them. The regression results suggests that almost two thirds of the decline in the employment rate in Spain between 2007 and 2014 was the result of the increase in real wages relative to potential GDP per capita. ${ }^{19}$ In other words, if real wages had not increased relative to potential GDP per capita, the employment rate would have fallen by $51 / 2$ percent rather than 15 percent.

\footnotetext{
${ }^{17}$ Using lagged real wages does not make much difference for the econometric results.

18 As explained in the previous section, in Finland and Sweden, this reflects the banking crises; in Portugal, the influx of the "retornados."

${ }^{19}$ To be precise: according to the regression results, of the decline in the employment rate between 2007 and 2014, 61 percent was the result of the increase in the real wage to potential GDP per capita ratio; 25 percent the result of the increase of the output gap, and 13 percent was unexplained.
} 
Table 9: Regression of Employment Gap on Output Gap and Real Wage to Potential GDP per Working Age Capita, 1970-2014

\begin{tabular}{rrrrrr}
\hline & output gap & t-value & real wages & t-value & $\mathrm{R} 2(\mathrm{adj})$ \\
\hline AUT & 0.51 & 8.80 & 0.01 & 0.63 & 0.64 \\
BEL & 0.56 & 9.24 & -0.02 & -1.21 & 0.66 \\
DNK & 0.56 & 7.31 & 0.01 & 0.38 & 0.54 \\
ESP & 1.03 & 14.80 & -0.03 & -1.79 & 0.84 \\
FIN & 0.75 & 11.66 & -0.02 & -0.62 & 0.76 \\
FRA & 0.52 & 10.29 & -0.01 & -0.39 & 0.70 \\
GBR & 0.57 & 6.73 & -0.00 & -0.09 & 0.50 \\
IRL & 0.73 & 9.41 & 0.00 & 0.02 & 0.68 \\
ITA & 0.48 & 5.95 & -0.00 & -0.22 & 0.43 \\
JPN & 0.24 & 3.46 & -0.00 & -0.36 & 0.19 \\
NLD & 0.55 & 7.62 & -0.01 & -0.72 & 0.56 \\
PRT & 0.48 & 10.89 & -0.00 & -0.10 & 0.73 \\
SWE & 0.61 & 6.82 & -0.01 & -0.18 & 0.50 \\
USA & 0.64 & 11.32 & -0.01 & -0.71 & 0.74 \\
\hline
\end{tabular}

Table 10: Comparison of Regression of Employment Rate on Output Gap With and Without Wages

\begin{tabular}{rrr}
\hline & R2 (adj) without Wages & R2 (adj) with Wages \\
\hline AUT & 0.10 & 0.41 \\
BEL & 0.07 & 0.82 \\
DNK & 0.42 & 0.48 \\
ESP & 0.17 & 0.83 \\
FIN & 0.28 & 0.27 \\
FRA & 0.14 & 0.19 \\
GBR & 0.25 & 0.47 \\
IRL & 0.24 & 0.70 \\
ITA & 0.08 & 0.56 \\
JPN & 0.02 & 0.69 \\
NLD & 0.01 & 0.95 \\
PRT & 0.06 & 0.21 \\
SWE & 0.17 & 0.15 \\
USA & 0.08 & 0.85 \\
\hline
\end{tabular}


Figure 23: Breakdown of Change in Employment Rate Since 2007

(Logs)

Spain

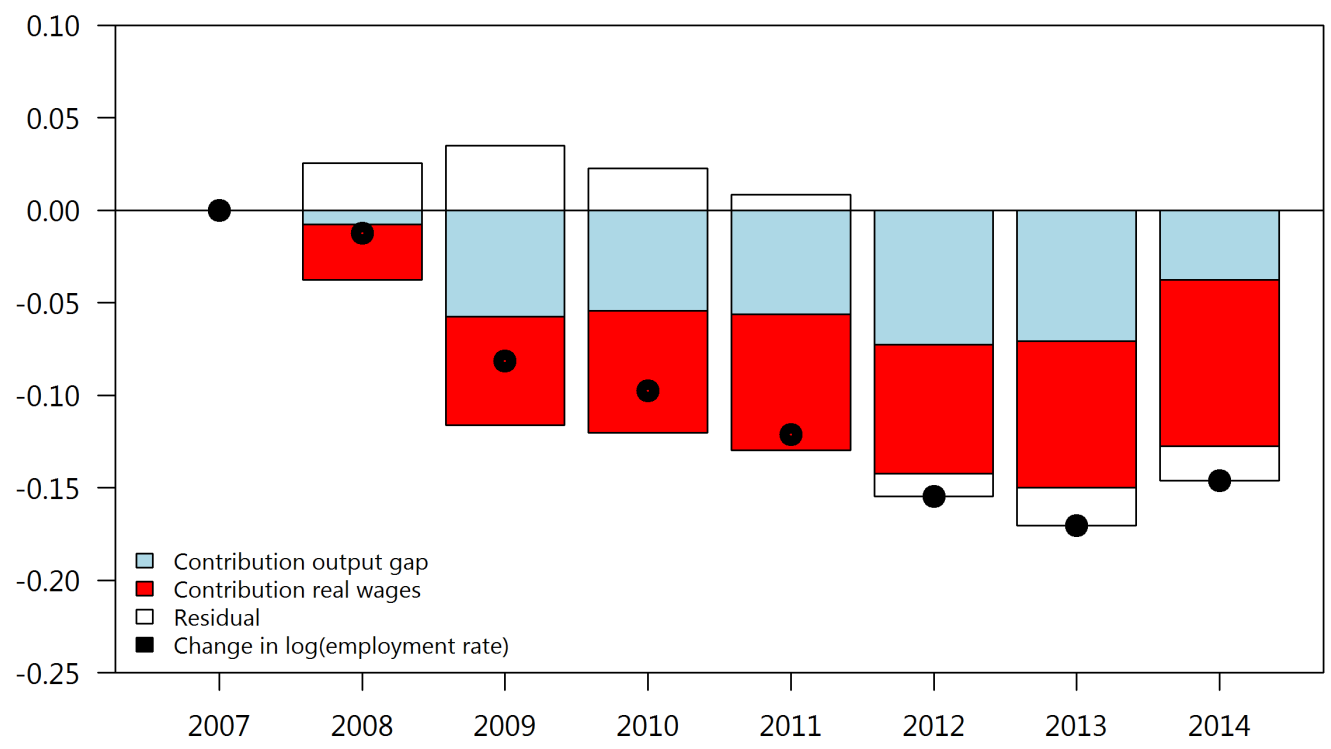

United Kingdom

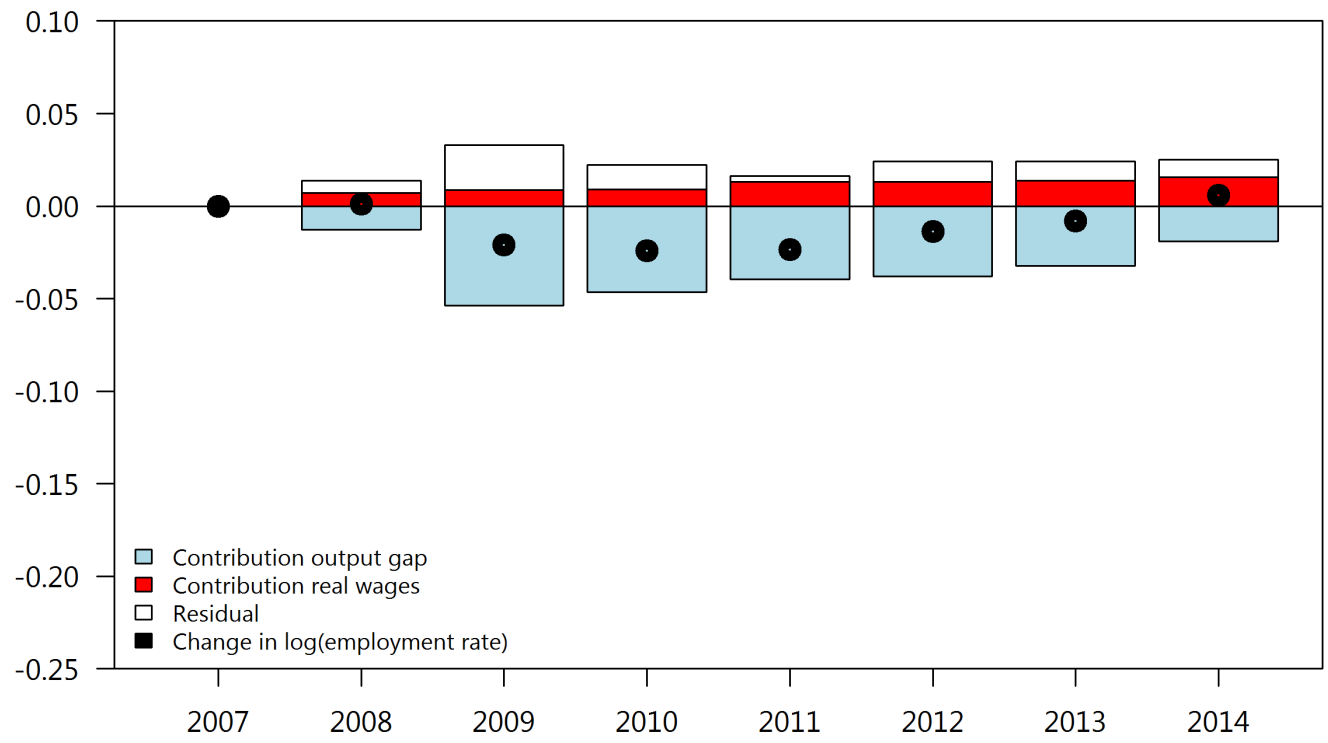




\subsection{Sensitivity Analysis}

In section 3.2 we showed that using different values for $\lambda$ has a big impact on our output gap estimates. Do they also make a difference for our regression results? And how do they affect our estimates of the contribution of the output gap and the real wage variable to changes in the employment rate?

Figure 24 shows that using different values for $\lambda$ not only affects the output gap estimates, but also the real wage variable. For example, for Spain:

- With a $\lambda$ of 1600 , we have a high post-2007 unemployment and output gap. The NAIRU has not increased much, but neither has our wage variable, as growth of potential GDP per working age capita has not declined much.

- If $\lambda$ is 100 , we have a much lower unemployment and output gap. The NAIRU has increased more, but so has our wage variable, as growth of potential GDP per working age person has slowed more sharply.

- If $\lambda$ is 6.25 the unemployment and output gap are even lower, and the NAIRU and our wage variable have increased even more.

Interestingly, differences in $\lambda$ do not seem to affect our regression results much. Tables 11 and 12 show the regression results of equation (29) if we use a $\lambda$ of 1600 and 6.25. The regression results are not very different from those in Table 8 - see Table 13. The real wage coefficients are very similar, while the coefficients for output gaps differ, but not in a systemic way. For some countries (including the United Kingdom), a higher $\lambda$ results in a higher coefficient of the output gap, while for other countries (including Spain) the coefficient is lower.

Of course, if coefficients in the regression equation are similar, but variations in the exogenous variables differ, the contributions of the exogenous variables should differ as well. This is borne out by comparing Figures 23, 25 and 26. The higher the value of $\lambda$, the smaller the estimated contribution of real wages to employment changes, and the larger the contribution of the changes in the output gap.

What is important, however, is whether a $\lambda$ of $6.25,100$ or 1600 is used, the behavior of real wage growth always exacerbates employment losses in Spain, and moderates those in the United Kingdom - and these results can be generalized to less dramatic cases. 
Figure 24: Spain: Output Gap and Real Wage Variable under different Lambdas (Percent)

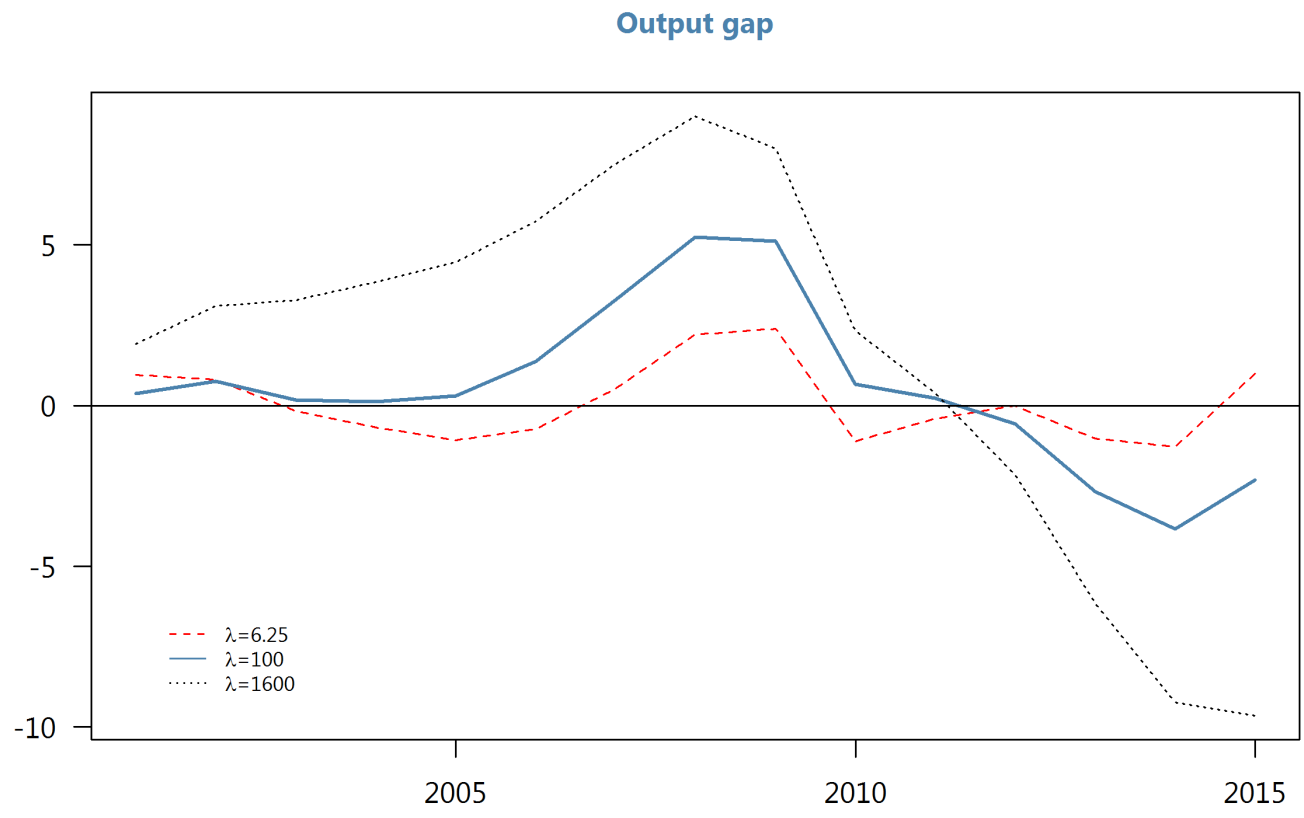

Ratio of Real Wages to Potential GDP Per Working Age Capita (Deviation from 2007, percent)

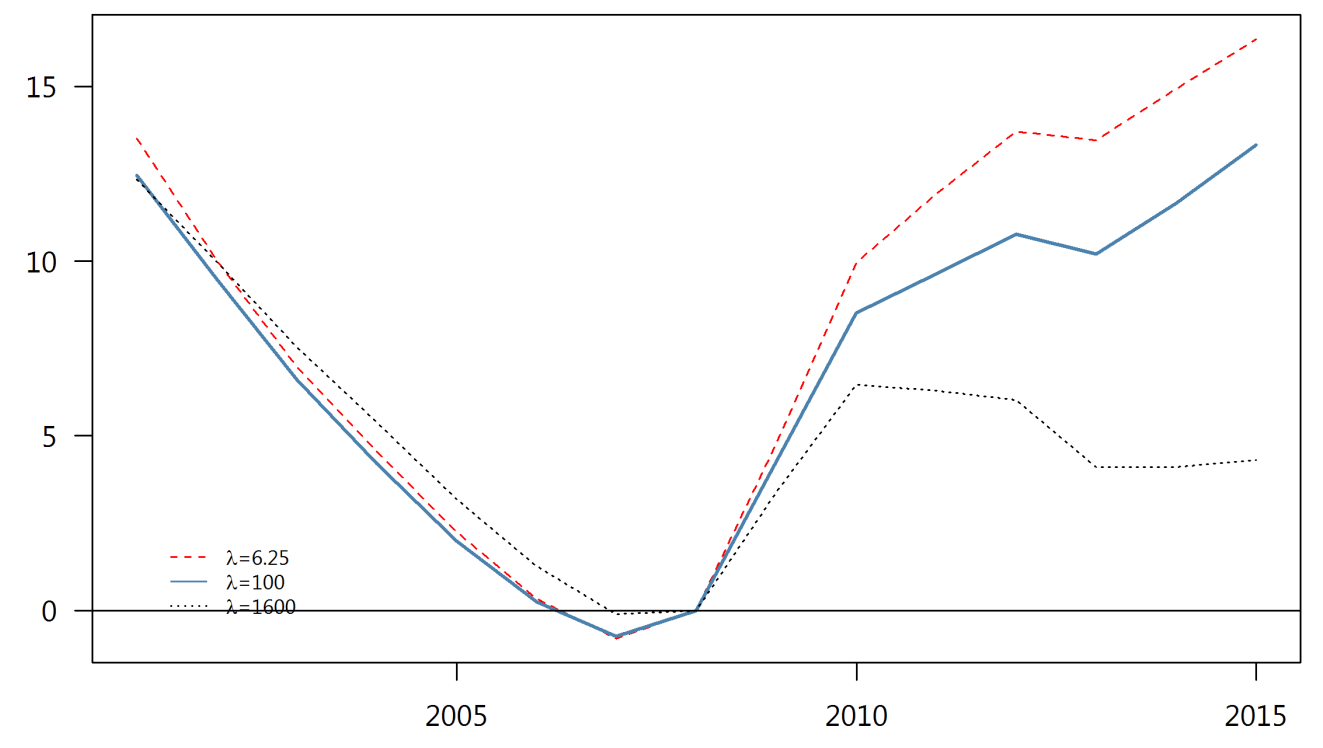


Table 11: Regression of Employment Rate on Output Gap and Real Wage to Potential GDP per Working Age Capita, 1970-2014, lambda=1600

\begin{tabular}{rrrrrr}
\hline & output gap & t-value & real wages & t-value & R2 (adj) \\
\hline AUT & 0.59 & 3.74 & -0.38 & -5.04 & 0.39 \\
BEL & 0.84 & 8.14 & -0.53 & -13.43 & 0.83 \\
DNK & 0.49 & 6.14 & -0.10 & -1.94 & 0.47 \\
ESP & 1.13 & 7.94 & -0.68 & -11.90 & 0.84 \\
FIN & 0.73 & 4.32 & 0.05 & 0.33 & 0.28 \\
FRA & 0.56 & 3.34 & -0.13 & -1.92 & 0.20 \\
GBR & 0.69 & 6.59 & -0.27 & -4.21 & 0.53 \\
IRL & 0.78 & 7.79 & -0.28 & -7.04 & 0.76 \\
ITA & 0.39 & 2.62 & -0.34 & -6.63 & 0.54 \\
JPN & 0.20 & 2.41 & -0.22 & -9.94 & 0.69 \\
NLD & 0.82 & 8.46 & -0.85 & -25.76 & 0.95 \\
PRT & 0.41 & 1.90 & 0.40 & 3.27 & 0.30 \\
SWE & 0.56 & 3.01 & -0.04 & -0.35 & 0.14 \\
USA & 0.82 & 8.15 & -0.58 & -14.63 & 0.86 \\
\hline
\end{tabular}

Table 12: Regression of Employment Rate on Output Gap and Real Wage to Potential GDP per Working Age Capita, 1970-2014, lambda=6.25

\begin{tabular}{rrrrrr}
\hline & output gap & t-value & real wages & t-value & R2 $(\mathrm{adj})$ \\
\hline AUT & 0.51 & 1.43 & -0.39 & -4.94 & 0.37 \\
BEL & 0.70 & 2.40 & -0.55 & -12.87 & 0.79 \\
DNK & 0.62 & 3.21 & -0.17 & -3.17 & 0.32 \\
ESP & 1.36 & 2.26 & -0.74 & -13.38 & 0.82 \\
FIN & 0.94 & 2.08 & -0.18 & -1.39 & 0.11 \\
FRA & 0.70 & 1.62 & -0.16 & -2.16 & 0.12 \\
GBR & 0.57 & 2.20 & -0.34 & -4.59 & 0.38 \\
IRL & 0.87 & 1.88 & -0.36 & -9.08 & 0.67 \\
ITA & 0.41 & 1.11 & -0.34 & -7.12 & 0.53 \\
JPN & 0.34 & 2.04 & -0.22 & -9.87 & 0.69 \\
NLD & 0.47 & 1.67 & -0.85 & -28.04 & 0.95 \\
PRT & 0.87 & 1.92 & 0.43 & 3.11 & 0.19 \\
SWE & 0.77 & 1.83 & -0.10 & -0.84 & 0.05 \\
USA & 0.77 & 3.77 & -0.60 & -14.72 & 0.84 \\
\hline
\end{tabular}


Table 13: Comparision of Regression Coefficients for Different Lambdas

\begin{tabular}{rrrrrrr}
\hline & gap, 6.25 & gap, 100 & gap, 1600 & wage, 6.25 & wage, 100 & wage, 1600 \\
\hline AUT & 0.51 & 0.79 & 0.59 & -0.39 & -0.36 & -0.38 \\
BEL & 0.70 & 0.97 & 0.84 & -0.55 & -0.54 & -0.53 \\
DNK & 0.62 & 0.69 & 0.49 & -0.17 & -0.12 & -0.10 \\
ESP & 1.36 & 1.22 & 1.13 & -0.74 & -0.72 & -0.68 \\
FIN & 0.94 & 1.04 & 0.73 & -0.18 & 0.01 & 0.05 \\
FRA & 0.70 & 0.73 & 0.56 & -0.16 & -0.14 & -0.13 \\
GBR & 0.57 & 0.76 & 0.69 & -0.34 & -0.30 & -0.27 \\
IRL & 0.87 & 0.96 & 0.78 & -0.36 & -0.33 & -0.28 \\
ITA & 0.41 & 0.69 & 0.39 & -0.34 & -0.33 & -0.34 \\
JPN & 0.34 & 0.32 & 0.20 & -0.22 & -0.22 & -0.22 \\
NLD & 0.47 & 0.87 & 0.82 & -0.85 & -0.85 & -0.85 \\
PRT & 0.87 & 0.47 & 0.41 & 0.43 & 0.39 & 0.40 \\
SWE & 0.77 & 0.77 & 0.56 & -0.10 & -0.02 & -0.04 \\
USA & 0.77 & 0.79 & 0.82 & -0.60 & -0.59 & -0.58 \\
\hline
\end{tabular}


Figure 25: Breakdown of Change in Employment Rate Since 2007, lambda $=6.25$ (Logs)

Spain

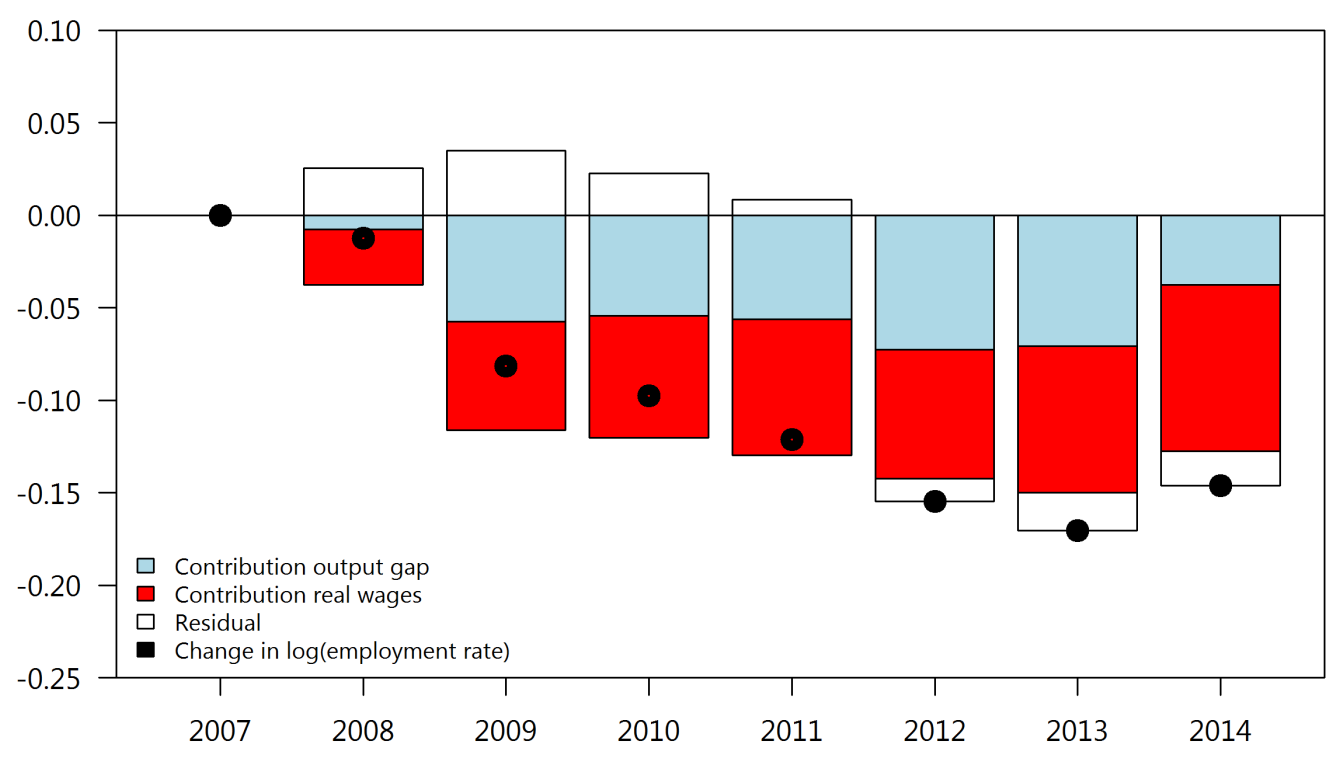

United Kingdom

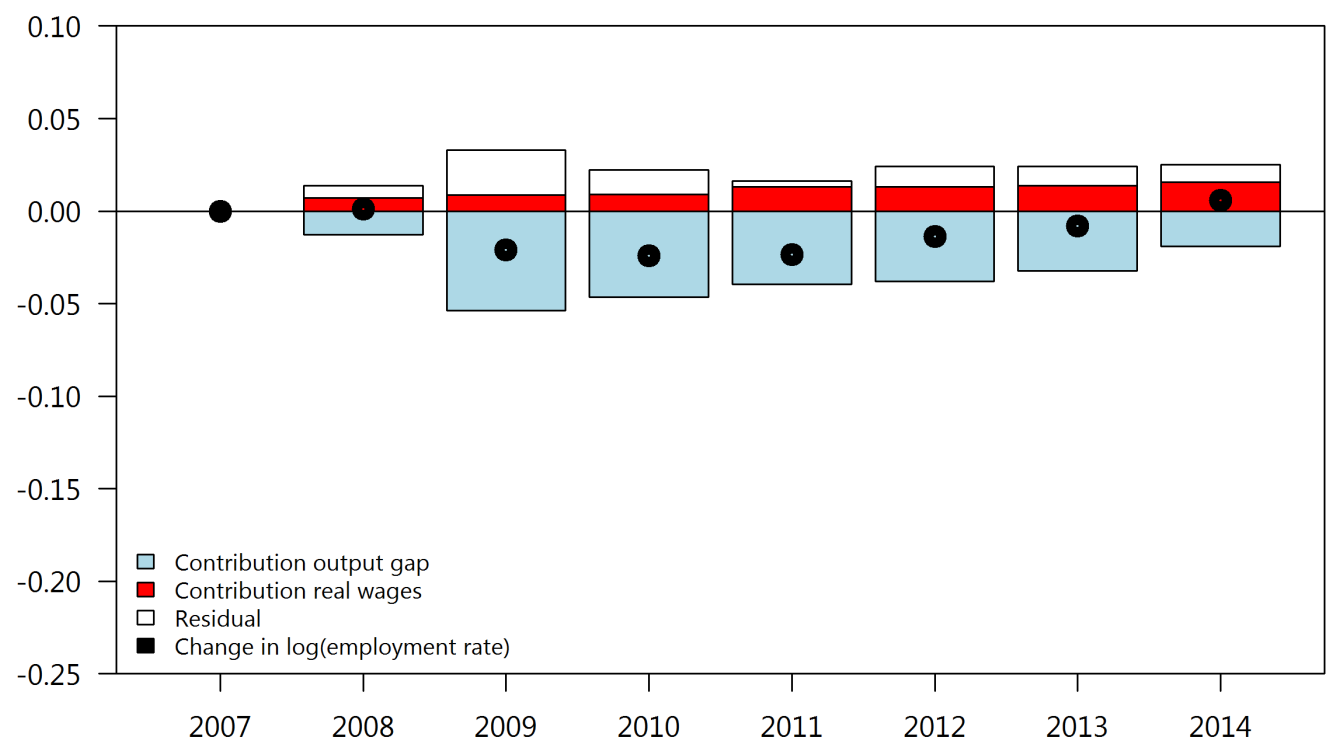


Figure 26: Breakdown of Change in Employment Rate Since 2007, lambda=1600

(Logs)

Spain

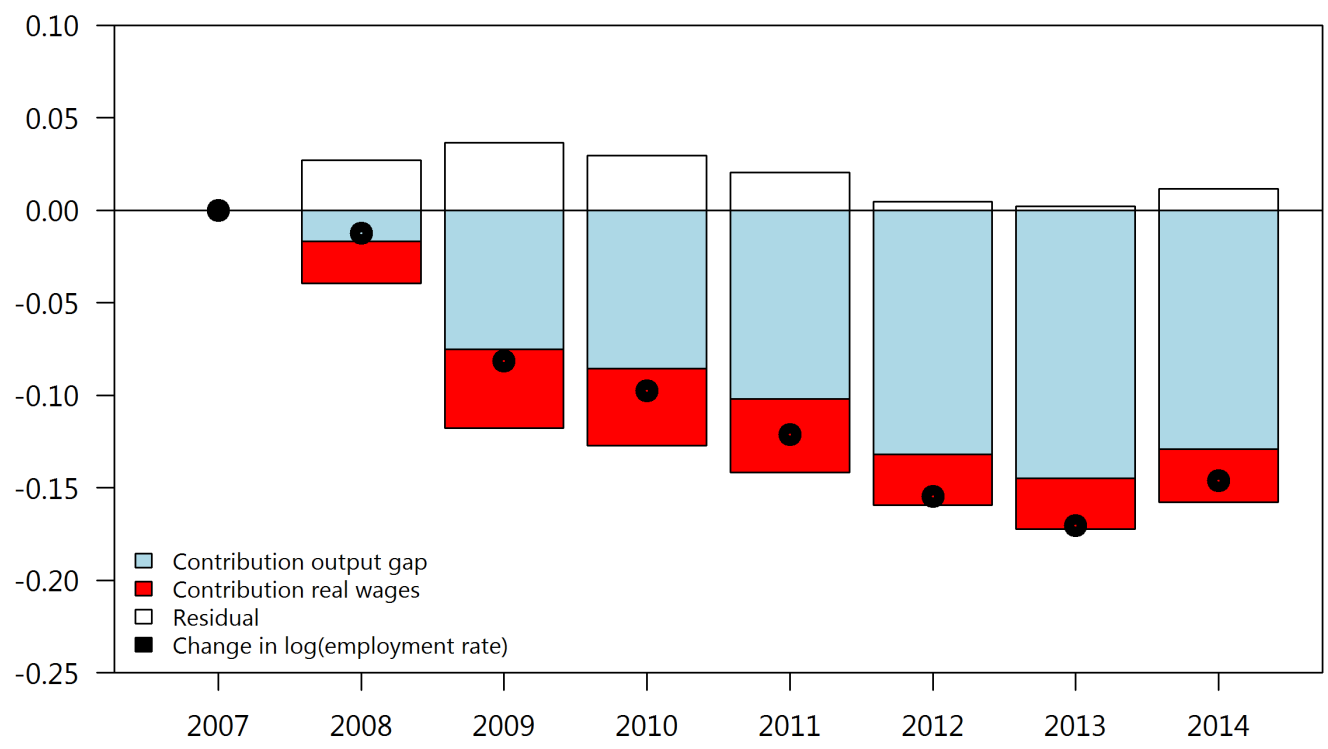

United Kingdom

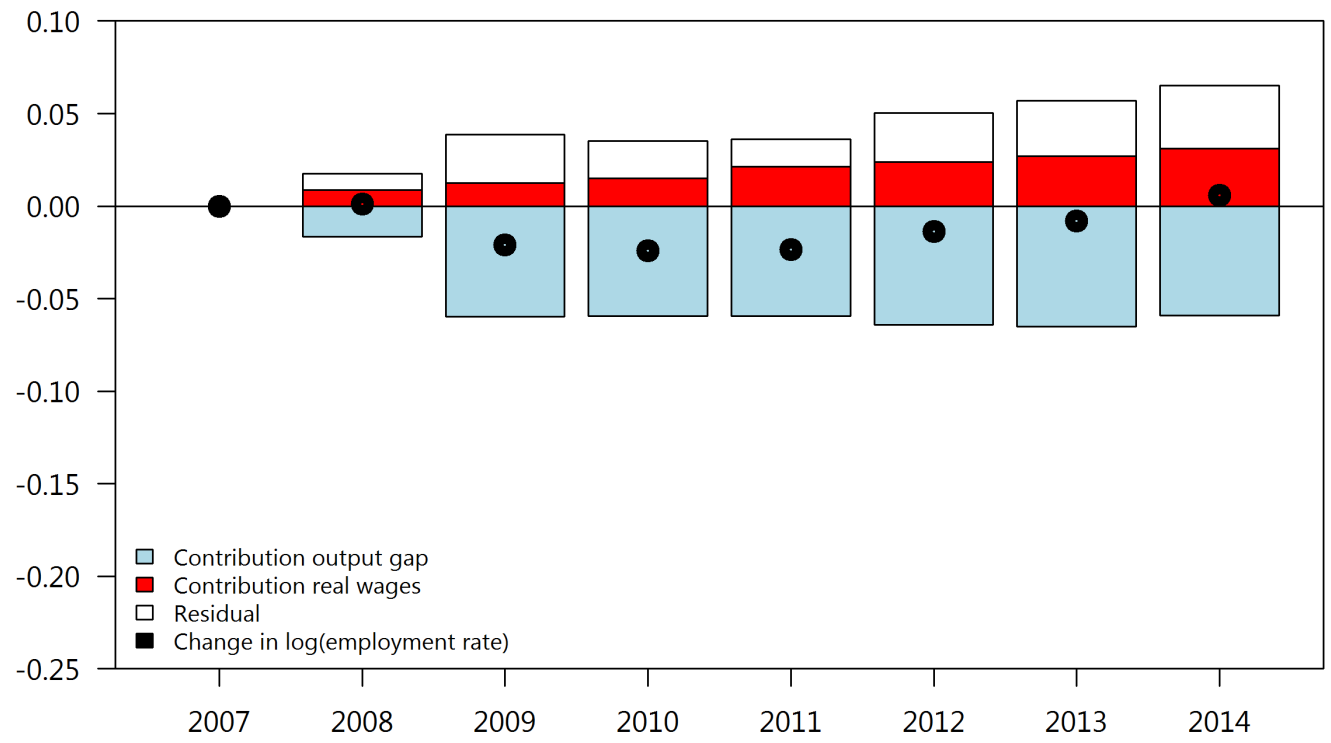




\section{Conclusion}

There have been large differences in employment growth among advanced countries in the 2007-2014 period. It is well established that differences in output growth account for part of these differences in employment and unemployment. This paper shows, however, that including the effects of real wage developments provides a more complete explanation.

In a sample of 14 countries for the 1970-2014 period, changes in the output gap explain only a portion of the changes in unemployment rates. This suggests that economists should not focus only on unemployment gaps and output gaps, but also on the overall unemployment rate and potential GDP growth. A significant part of the change in unemployment is found to be structural; the same applies to employment. The structural change in employment can be explained by a real wage indicator derived from standard neoclassical production theory - that is, the ratio of the average real wage to potential GDP per working age capita. In the longer run, what happens to real wages relative to potential GDP per working age person, may be more important than the size of the output gap at some point in the cycle.

The conventional partition of output and employment (or unemployment) into structural and cyclical components by means of an HP filter is inevitably somewhat arbitrary - that is, dependent on the parameterization of the filter - and far from straightforward. It is important, therefore, to be sure that the results of any analysis that depends on HP mechanics are true of the real-world terrain and not merely of the particular map employed.

It should be recognized that using higher values for $\lambda$ increases the contribution of the output gap to post-2007 employment losses and reduces the contribution of real wages. However, this is not because a higher value of $\lambda$ increases the output gap coefficient and reduces the real wage coefficient in our regressions - these coefficients do not change much when different values of $\lambda$ are used. Rather, it is because a higher $\lambda$ makes the output gaps larger and the increase of our wage pressure variable smaller - the latter because the denominator (potential GDP per working age person) increases more. Ultimately, the relative contributions of the output gap and real wages thus depend on what has happened with potential output growth. If - as we believe - it has declined, the contribution of real wage adjustment has been relatively important; whereas if it has not declined much, then the output gap has been more important. The marginal impact of higher real wages on employment itself is not sensitive to the particular value of $\lambda$ used.

The argument that movements in unemployment rates cannot be understood well by looking at cyclical developments only is similar to an argument made by Summers (2014):

"Unfortunately, almost all work in both the New Classical and New Keynesian traditions has focused on the second moment (the variance) of output and employment. This thinking presumes that, with or without policy intervention, the workings of the market will eventually restore full employment and 
eliminate output gaps. The only questions are about the volatility of output and employment around their normal levels. What has happened in the last few years suggests that the second moment is second-order relative to the first moment - the average level of output and employment through time."

The results in this paper suggest a number of areas for further research. We have treated output and real wages as exogenous. In this framework, differences in employment performance across countries can be explained largely by differences in the behavior of wages relative to potential. But what explains the difference in wage behavior - why are wages much more flexible in some countries? And what explains the collapse of potential growth? Some have argued that the root of the problem has been the prolonged weakness in aggregate demand, which has undermined growth potential by creating hysteresis in the labor market. But if inadequate demand has everywhere been the driving force, then why has productivity performance varied so widely, accelerating in some countries, while slowing in others? These topics are beyond the scope of this paper, but essential to a more complete understanding of cross-country differences in employment growth. 


\section{References}

Artus, Jacques R (1984), An Empirical Analysis of the Disequilibrium Real Wage Rate Hypothesis, NBER Working Paper No. 1404, July 1984.

Backus, D. K. and P. J. Kehoe (1992), International evidence on the historical properties of business cycles, The American Economic Review, 864-888.

Ball, Laurence M., Daniel Leigh and Prakash Loungani (2013) Okun's Law: Fit at Fifty?, NBER Working Paper No. 18668.

Blanchard, Olivier (1997), The Medium Run, Brookings Papers on Economic Activity, Vol. 1997, No. 2, pp. 89-158.

Bruno, Michael and Jeffrey Sachs (1979), Supply vs. Demand Approaches to the Problem of Stagflation, NBER Working Paper No. 382, August.

Bruno, Michael and Jeffrey Sachs (1985), The Economics of Worldwide Stagflation, Cambridge MA: Harvard University Press.

David, P. A. and T. van de Klundert, (1965), Biased efficiency growth and capital-labor substitution in the US, 1899-1960, American Economic Review, 55(3):357-394.

Hodrick, R. J. and E. C. Prescott (1997), Postwar US business cycles: an empirical investigation, Journal of Money, Credit, and Banking, 1-16.

Jaumotte, Florence (2011), The Spanish Labor Market in a Cross-Country Perspective, IMF Working Paper WP/11/11.

Klump, Rainer, Peter McAdam and Alpo Willman (2011), The Normalized CES Production Function Theory and Empirics, ECB Working Paper Series, No 1294/February.

Lipschitz, Leslie and Susan M. Schadler (1984), Relative Prices, Real Wages, and Macroeconomic Policies: Some Evidence from Manufacturing in Japan and the United Kingdom, IMF Staff Papers, Vol 31, No. 2 (June 1984), pp. 303-338.

Martin, Robert, Teyanna Munyan, and Beth Anne Wilson (2015), Potential Output and Recessions: Are We Fooling Ourselves?, International Finance Discussion Papers 1145.

Miller, Eric, An Assessment of CES and Cobb-Douglas Production Functions, Congressional Budget Office Working Paper 2008-05, 2008.

Ravn, Morten O. and Harald Uhlig (2002), On adjusting the Hodrick-Prescott Filter for the Frequency of Observations, The Review of Economics and Statistics, Volume 82, No 2, May, pp. 371-380.

Sachs, Jeffrey (1983), Real Wages and Unemployment in the OECD Countries, Brookings Papers on Economic Activity, Vol. 1983, No. 1 (1983), pp. 255-304.

Summers, Laurence H. (2014), "Reflections on the "New Secular Stagnation Hypothesis" in Secular Stagnation: Facts, Causes and Cures, edited by Coen Teulings and Richard Baldwin, CEPR Press.

Thimann, Christian (2015), The Microeconomic Dimensions of the Eurozone Crisis and Why European Politics cannot Solve Them, Journal of Economic Perspectives, Volume 29, Number 3, pp. 141-164. 


\section{Data sources}

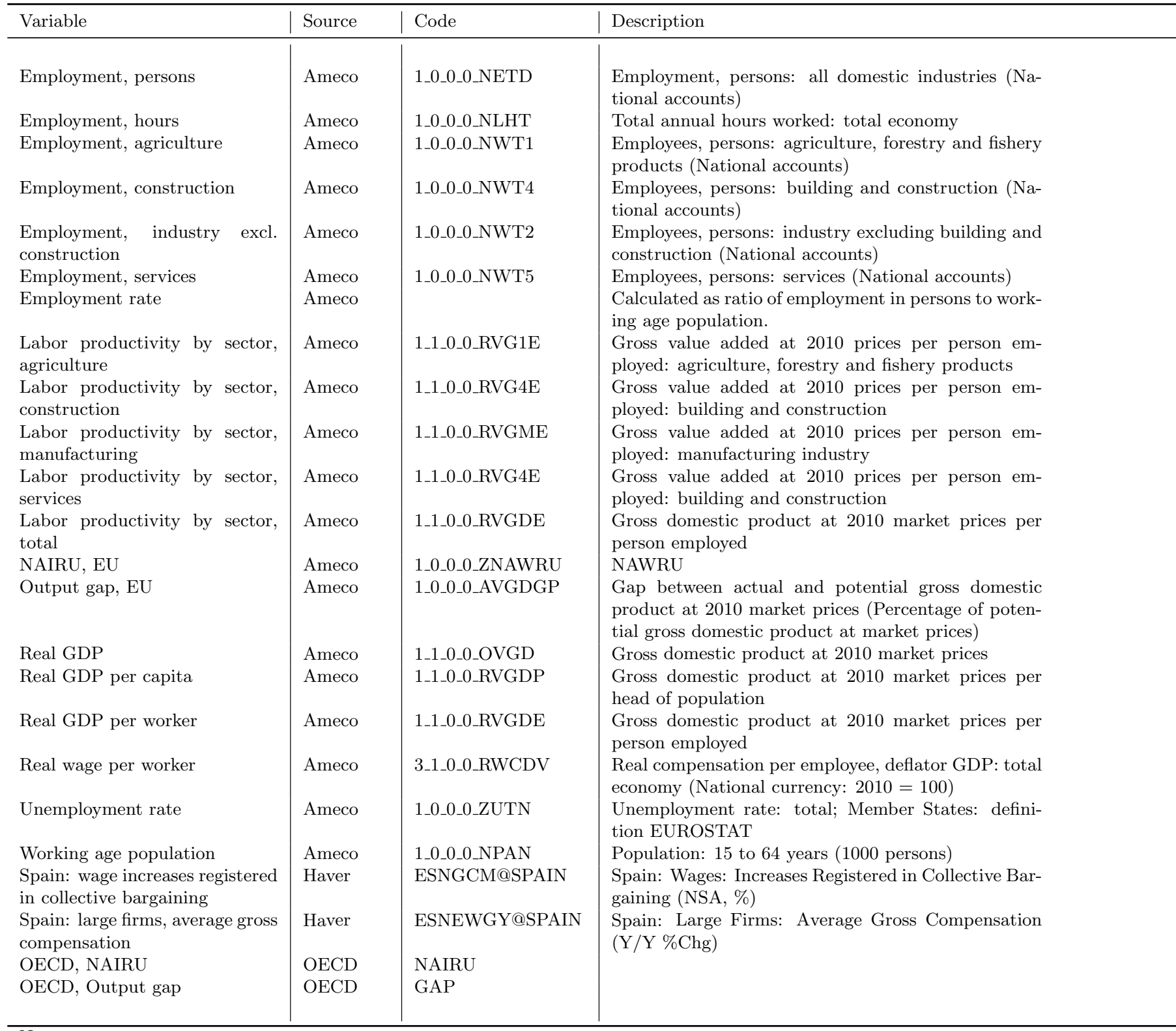

Notes:

AMECO is the annual macro-economic database of the European Commission's Directorate General for Economic and Financial Affairs (DG ECFIN). See http://ec.europa.eu/economy_finance/db_indicators/ameco/index_en.htm

OECD Economic Outlook Database can be accessed at https://stats.oecd.org/index.aspx?queryid=51396. 


\section{Annex 1: Derivation using a CES-function}

We use the CES-function specification proposed by David and van de Klundert (1965): ${ }^{20}$

$$
Y=\left[\left(A_{K} K\right)^{\rho}+\left(A_{L} L\right)^{\rho}\right]^{1 / \rho}
$$

where $A_{K}$ represents capital-augmenting technological change and $A_{L}$ represents laboraugmenting progress.

The marginal product of labor is equal to the wage, which implies that

$$
W=A_{L}^{\frac{\sigma-1}{\sigma}}\left(\frac{Y}{L}\right)^{\frac{1}{\sigma}}
$$

where $\rho=\frac{\sigma-1}{\sigma}$. We can rewrite this as:

$$
\frac{W}{A_{L}}=A_{L}^{\frac{-1}{\sigma}}\left(\frac{Y}{L}\right)^{\frac{1}{\sigma}}
$$

Taking logs, we can derive that:

Assuming that

$$
\log \frac{Y}{L}=\log \left(A_{L}\right)+\sigma \log \left(\frac{W}{A_{L}}\right)
$$

$$
A_{L, t}=e^{\gamma t} A_{L, 0}
$$

we can deduce that

$$
\log \left(\frac{Y_{t}}{L_{t}}\right)=\log \left(\frac{Y_{0}}{L_{0}}\right)+\gamma t+\sigma \log \left(\frac{W_{t}}{e^{\gamma t} W_{0}}\right)
$$

\section{Interpreting $\gamma$ as TFP growth}

If we assume that capital augmenting progress grows at the same rate as labor-augmenting technological progress:

$$
A_{K, t}=e^{\gamma t} A_{K, 0}
$$

We can rewrite equation (30) as

$$
Y_{t}=\left[e^{\rho \gamma t}\left[\left(A_{K, 0} K\right)^{\rho}+\left(A_{L, 0} L\right)\right]^{\rho}\right]^{\frac{1}{\rho}}
$$

which can be rewritten as:

$$
Y_{t}=e^{\gamma t}\left[\left(A_{K, 0} K\right)^{\rho}+\left(A_{L, 0} L\right)^{\rho}\right]^{\frac{1}{\rho}}
$$

In this case, $\gamma$ can be interpreted as the growth rate of TFP.

\footnotetext{
${ }^{20}$ This exposition is based on Miller (2008, page 9).
} 


\section{Annex 2: The Wage Share}

We can rewrite equation (13) as

$$
\frac{L_{t}}{Y_{t}}=\left(\frac{L_{0}}{Y_{0}}\right) e^{-\gamma t}\left(\frac{e^{\gamma_{t}} W_{0}}{W_{t}}\right)^{\beta}
$$

This implies that the wage share is equal to:

$$
\frac{W_{t} L_{t}}{Y_{t}}=\left(\frac{L_{0}}{Y_{0}}\right) e^{-\gamma t} W_{t}\left(\frac{e^{\gamma_{t}} W_{0}}{W_{t}}\right)^{\beta}
$$

If wages grow at rate $\gamma$ then we have

$$
W_{t}=e^{\gamma t} W_{0}
$$

Substituting equation (41) in (40) we get:

$$
\frac{W_{t} L_{t}}{Y_{t}}=\frac{W_{0} L_{0}}{Y_{0}}
$$

which means that the wage share is constant. 


\section{Annex 3: Derivation using a Cobb-Douglas production function}

We will now simplify the previous analysis and assume that output is determined by a Cobb-Douglas production function:

$$
Y=A K^{\alpha} L^{1-\alpha}
$$

The real wage rate is equal to the marginal product of labor. This implies that

$$
W=(1-\alpha)\left(\frac{Y}{L}\right)
$$

We can rewrite equation (44) as:

$$
W=(1-\alpha)\left(\frac{Y}{N}\right)\left(\frac{N}{L}\right)
$$

where $N$ denotes the working age population. From this it follows that:

$$
\left(\frac{L}{N}\right)=(1-\alpha) \frac{\left(\frac{Y}{N}\right)}{W}
$$

In other words, the higher real wages per worker are relative to GDP per working age person, the lower the employment rate.

Note that in this example, the wage share remains constant, and does not increase if real wages rise. In other words, lower employment is not the result of a higher wage share. 